\title{
CONSIDERACIONES ÉTICAS PARA LA ELABORACIÓN DE INFORMES PSICOLÓGICOS CLÍNICOS EN EL CONTEXTO MEXICANO
}

\author{
Diana Moreno Rodríguez, Norma Edith Muñoz Villegas, \\ Pamela Rodríguez Palacios y Christian Ivan Gil Dávila \\ Facultad de Estudios Superiores Iztacala UNAM \\ México
}

\begin{abstract}
RESUMEN
En la práctica profesional, el psicólogo clínico tiene la obligación de comunicar los resultados de su actividad mediante un informe claro y preciso. Dicho informe es conocido en la literatura como informe psicológico clínico (IPC). El objetivo de este artículo es presentar 10 recomendaciones básicas para la elaboración de un IPC; estas recomendaciones incluyen elementos de formato y contenido, así como diversos aspectos relacionados con la ética. Para apoyar cada una de las recomendaciones se consultaron diferentes fuentes de información publicadas por asociaciones de psicólogos reconocidas en México y en el extranjero, así como autoridades académicas y de la salud. Se presentan dichas recomendaciones, su definición, así como una tabla documental con las fuentes, numerales, artículos y leyes, entre otros aspectos, que apoyan cada una de las recomendaciones. Se concluye la necesidad de que los psicólogos en formación conozcan dichas sugerencias y los documentos referidos.
\end{abstract}

Palabras Clave:

informe psicológico clínico, confidencialidad, código de ético del psicólogo, evaluación psicológica, bioética.

\section{ETHICAL CONSIDERATIONS FOR THE PREPARATION OF CLINICAL PSYCHOLOGICAL REPORTS IN THE MEXICAN CONTEXT}

\begin{abstract}
In professional practice, the clinical psychologist has the obligation to communicate the results of his activity through a clear and precise report. This report is known in the literature as the Clinical Psychological Report (CPR). The objective of this work is to present 10 basic recommendations for the elaboration of an CPR, these recommendations include elements of format and content, as well as various aspects related to ethics. To support each of the recommendations, different sources of information published by recognized associations of psychologists in Mexico and abroad, as well as academic and health authorities, were consulted. These recommendations, their definition, as well as a documentary table with the sources, and numerals, articles, laws, etc., that support each of the recommendations are presented. The need for psychologists in training to know these suggestions and the referred documents is concluded.
\end{abstract}

Keywords:

clinical psychological report, confidentiality, code of ethics of the psychologist, psychological assessment, bioethics

Bitácora del Artículo:

| Recibido: 31 de Diciembre de 2020 | Aceptado 19 de Mayo de 2021 | Publicado en línea: Julio - Diciembre de 2021 | 


\title{
CONSIDERACIONES ÉTICAS PARA LA ELABORACIÓN DE INFORMES PSICOLÓGICOS CLÍNICOS EN EL CONTEXTO MEXICANO
}

\author{
Diana Moreno Rodríguez, Norma Edith Muñoz Villegas, \\ Pamela Rodríguez Palacios y Christian Ivan Gil Dávila \\ Facultad de Estudios Superiores Iztacala UNAM \\ México
}

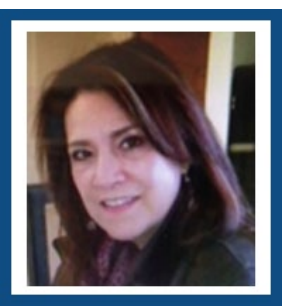

Diana Moreno Rodríguez

FES- Iztacala, UNAM

Correo: dianamoren090@gmail.com

Es doctora en Educación: diagnóstico, medida y evaluación de la intervención educativa, por la Universidad Anáhuac y Universidad Complutense de Madrid. Sus líneas de investigación abarcan la psicología experimental, la educación y la salud. Es docente en pregrado y posgrado, en asignaturas relacionadas con la metodología de la investigación. Actualmente Pertenece al Sistema Nacional de Investigadores como investigador nacional Nivel 1.

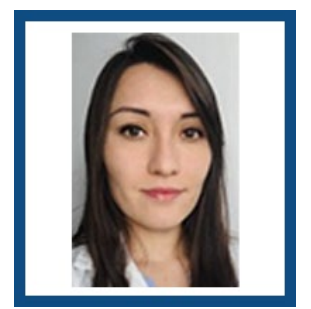

Norma Edith Muñoz Villegas

FES- Iztacala, UNAM

Correo:edith_598011@hotmail.com

Licenciada en Psicología con formación cognitivo conductual, egresada de la Universidad Nacional Autónoma de México (UNAM). Actualmente Estudiante de la Residencia en Medicina Conductual, del Programa de Maestría y Doctorado de la UNAM. Experiencia profesional en el área clínica con pacientes con enfermedades crónico-degenerativas en hospitalización.

\section{CONTRIBUCIÓN DE LOS AUTORES}

Diana Moreno Rodríguez estuvo a cargo de la coordinación, revisión, corrección y redacción del trabajo | Norma Edith Muñoz Villegas participó en la redacción, corrección y búsqueda bibliográfica | Pamela Rodríguez Palacios colaboró en la redacción, corrección y búsqueda bibliográfica | Christian Iván Gil Dávila participó en la redacción, corrección y búsqueda bibliográfica

\section{AGRADECIMIENTOS}

[Agradacimientos por parte de los autores]

\section{DATOS DE FiLIACIÓN dE los Autores}

Facultad de Estudios Superiores Iztacala, UNAM

\section{(a)

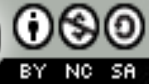

Copyright: (C 2021 Moreno-Rodríguez, D.; Muñoz-Villegas, N.E.; Rodríguez-Palacios, P.; \& Gil-Dávila, C.I.

Este es un artículo de acceso abierto distribuido bajo los términos de la licencia Creative Commons Reconocimiento-NoComercial 4.0 Internacional, por lo que su contenido gráfico y escrito se puede compartir, copiar y redistribuir total o parcialmente sin necesidad de permiso expreso de sus autoras con la única condición de que no se puede usar con fines directamente comerciales y los términos legales de cualquier trabajo derivado deben ser los mismos que se expresan en la presente declaración. La única condición es que se cite la fuente con referencia a la Revista Digital Internacional de Psicología y Ciencia Social y a sus autoras. 


\section{TABLA DE CONTENIDO}

INTRODUCCIÓN

MÉTODO

PRECISIONES TEÓRICAS

Poseer la cualificación, 263

Respetar la dignidad, libertad, autonomía e intimidad del

cliente, 264

Respetar y cumplir el derecho y el deber de informar al cliente, 264

Organización de los contenidos del informe, 264

Proceso de evaluación, hipótesis formuladas y justificación de

conclusiones, 264

Cuidar el estilo, 264

Mantener la confidencialidad y la secrecía profesional, 265

Solicitar el consentimiento informado, 265

ANÁLISIS Y DISCUSIÓN

CONCLUSIONES

REFERENCIAS

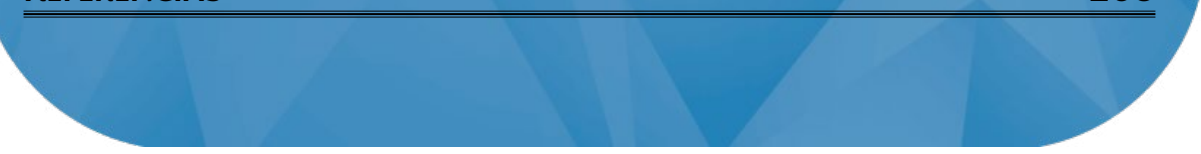




\section{INTRODUCCIÓN}

$\mathbf{E}$ I quehacer del psicólogo puede describirse como un proceso que involucra actividades variadas y diferenciadas en cada etapa de dicho proceso. El producto de estas actividades y juicios derivados de éstas se verán reflejados en un documento denominado "informe psicológico clínico" (IPC). El Dicho informe es un documento con rigurosidad científica y objetividad, es un instrumento de comunicación cuyo objetivo principal es dar a conocer los resultados del proceso de evaluación o intervención psicológica. En este documento se plasma la información esencial de la evaluación psicológica o proceso psicoterapéutico (Bustos, 2018; Heredia, Santaella y Somarriba, 2012; Pérez, Muñoz y Ausín, 2003).

Las cuatro funciones principales de un IPC según Wiener y Costaris (2012) son: 1) incrementar el entendimiento de los involucrados en el caso, de las habilidades cognitivas, conductuales, dificultades socioemocionales, así como los factores medioambientales que impiden un ajuste emocional del paciente (cliente); 2) proporcionar recomendaciones viables para efectuar una intervención que se adapte a las necesidades del cliente; 3) comunicar la información del diagnóstico y recomendaciones que se llevarán a cabo para una mejor adaptación del cliente, y 4) proporcionar un registro a largo plazo que pueda utilizarse en cualquier momento.

La estructura del IPC puede variar; sin embargo, se considera que expresa de manera organizada, sintética e integrada lo que se ha comprendido, valorado y juzgado del caso. En términos generales, el IPC en una modalidad oral o escrita incluye una descripción valorativa del cliente, además de las respuestas a preguntas específicas (Heredia et al., 2012).

En la literatura se puede encontrar una gran diversidad en la conformación de su estructura; no obstante, el IPC integra y combina un número importante de elementos; entre los más comunes están: fecha de inicio y término (evaluación/intervención), datos de identificación del paciente, historia del problema, descripción del proceso de evaluación, selección de pruebas, integración de diversos recursos de información, recomendaciones, conceptualización del caso, etcétera (Cattáneo, 2007; Fernández-Ballesteros y Calero, 2013; Groth-Marnat y Horvarth, 2006; Mancilla, 2011).
Wiener y Costaris (2012) indican que pareciera que el IPC está relacionado sólo con habilidades de escritura, de formato y de comunicación, es decir las relacionadas con el cómo comunicar las ideas de una manera efectiva y ordenada. Al respecto hay estudios que evalúan diferentes estilos de presentación de un IPC, en donde se demuestra que aquellos que se organizan en temáticas (vs datos de las pruebas), son los más aceptados entre los no especialistas, porque según los autores los temas sirven como organizadores para comprender mejor la información contenida en un IPC (Pelco, Ward, Coleman y Young, 2009). En otros estudios, y siguiendo con la lógica de destacar la estructura, formato y contenido de un IPC, Erikson y Maurex (2018) evaluaron —en un grupo de estudiantes la retroalimentación recibida por profesores y por los pares-la escritura de un IPC. Dicha retroalimentación versó acerca de cuatro dominios (aspectos formales, contenido, conocimiento y lenguaje); los resultados muestran que los estudiantes son capaces de recuperar la retroalimentación recibida e indicar un cambio significativo en los dominios evaluados en una segunda versión de sus informes.

Sin embargo las habilidades necesarias para desarrollar un IPC van más allá de la escritura, comunicación y estructura del IPC. Se requiere de una base sólida de considerandos éticos, del uso que se le dará a la evaluación, la necesidad del consentimiento informado y las implicaciones de la divulgación e interpretación de los resultados, entre otras cosas (Borda, Del Río, Pérez y Martín, 2002; Ormart, 2013). Para Arslan (2018) los psicólogos deben estar bien informados de las reglas, códigos, guías y principios que deben regir su actividad profesional. Pero para conducirse de manera ética no basta con conocer los códigos y guías existentes; se trata un problema de formación universitaria (Cristaldo, 2012; Díaz-Barriga, Pérez y Lara, 2016; Pasmanik y Winkler, 2009; Ochoa, 2018).

En los últimos años ha habido un cambio importante en la formación de los psicólogos; por una parte, las responsabilidades y compromisos de los profesionales de la psicología han de ajustarse a las demandas de un usuario más consciente de sus derechos como usuario de los servicios de salud (Organización Mundial de la Salud [OMS], 2017), y por otra, la infinidad de propuestas materializadas en documentos (leyes, códigos, manuales de estilo, decretos, etcétera) que de una u otra manera apoyan y hacen más complejas las actividades del psicólogo en cualquier ámbito de desarrollo profesional en el siglo XXI, todo esto permeado por una globalización inminente. Las fuentes que advierten acerca del fenómeno de la formación profesional como un fenómeno global son diversas; algunas de ellas indican los 
convenios internacionales, otras la necesidad de coordinar las políticas públicas para regular la acreditación y titulación entre los países de Latinoamérica, y otras - como los organismos internaciones- que reconocen la importancia de las cualificaciones relativas a la educación superior que trascienden las fronteras (Altbach, 2016; Fraile, 2006; UNESCO, 2019).

Todos estos elementos indican la necesidad de hacer un recuento de los elementos esenciales necesarios en la elaboración de un IPC. Para la propuesta desarrollada en este trabajo, y de acuerdo con la lógica de Pérez et al. (2003), primero se enuncia cada una de las recomendaciones de manera independiente, después se hace una descripción general, y enseguida se presenta una tabla documental en donde se enlistan las guías, leyes, decretos, artículos, manuales y/o documentos que apoyan dicha descripción.

Este trabajo, sin ser una revisión exhaustiva, representa una guía general de 10 recomendaciones para desarrollar IPC de calidad, teniendo como ejes rectores algunos elementos de formato y estilo, la ética profesional, la competencia profesional, la autonomía del cliente, la confidencialidad, el respeto a informar al cliente, las autoridades y los otros involucrados en el caso.

\section{MÉtodo}

Primero se hizo el listado, así como una definición precisa, de las 10 recomendaciones que conformarían este documento, mismas que fueron retomadas de Pérez et al. (2003). Una vez definidas, y mediante internet se procedió a consultar tres diferentes fuentes de información: 1) los códigos de ética tanto de la Sociedad Mexicana de Psicología (2010), como de la American Psychological Association (2017), ambos casos como referencias obligadas para los psicólogos de México, y en especial el segundo como referencia básica para el mundo globalizado del siglo XXI; es importante destacar que la gran mayoría de las asociaciones de psicología en el mundo han tomado como referencia básica el código de ética de la American Psychological Association (APA) para la estructuración del propio (Fierro, 2001); 2) se consideraron las instancias de gobierno relacionadas con la salud (instituciones de salud) y la bioética (instituciones de protección de datos personales), y 3) las fuentes de información académica que, en su modalidad de libros y manuales, constituyen parte de los currículos de los psicólogos en formación profesional, y que son lectura obligada en diversidad de asignaturas.

Para la selección de la información que sería incluida en este trabajo, se consideró como eje de consulta cada una de las 10 recomendaciones definidas; de este modo cada uno de los autores de este trabajo consultó y revisó las posibles fuentes de información y decidió su pertinencia con el criterio de la mención explícita de la temática o recomendación bajo análisis y la versión más reciente de la fuente consultada.

Después, y en repetidas ocasiones, los autores se reunieron y discutieron la pertinencia de las fuentes seleccionadas; en caso de haber discrepancia se analizaba el caso y se discutía hasta llegar un acuerdo respecto a la inclusión o exclusión de la fuente analizada. Es necesario mencionar que en algunos casos se eliminaron fuentes, en otros se sustituyeron por versiones más recientes y en otros más, y dado que la búsqueda se hizo de nuevo, se encontraron otras fuentes, acción que enriqueció el trabajo final.

Es importante indicar que en que la primera revisión se encontraron 10 fuentes diferentes, y 131 artículos (incisos, numerales, etcétera), relacionados con las 10 recomendaciones o ejes de análisis. En una última revisión se eliminaron dos fuentes, se sustituyeron cuatro fuentes por versiones más recientes, y se agregaron seis más, quedando un total 14 fuentes diferentes y 222 numerales. Asimismo, todas las fuentes documentales presentadas se muestran de manera textual; en algunos casos la instancia de emisión las denomina artículos, numerales, cláusulas breves o acotaciones, de ahí el formato disímil entre ellas.

\section{Precisiones teóricas}

\section{Poseer la cualificación}

La primera recomendación hace hincapié en que el profesional que elabore un IPC debe tener título y cédula profesional que lo acredite como licenciado en Psicología. Como profesional competente es necesario que se mantenga en constante formación; su competencia clínica debe ser de altísima calidad para hacer evaluaciones y diagnósticos psicológicos, lo que sólo se logrará con la actualización de sus conocimientos y habilidades profesionales. Aunado a ello, el profesional de la Psicología, al desempeñar cualquiera de sus funciones, incluidas la evaluación, la intervención o el informe psicológico, debe conocer cuál es su nivel de competencia y limitación profesional.

Otros aspectos que el psicólogo debe conocer son los principios éticos y legales vigentes del lugar en que ofrece sus servicios. Los documentos de apoyo relativos a la cualificación del evaluador en México se muestran en la tabla 1(ver en anexo). 


\section{Respetar la dignidad, libertad, autonomía e intimidad del cliente}

Se debe respetar la dignidad, la libertad, la autonomía y la intimidad del cliente; por tanto, el psicólogo tiene la obligación de decidir qué tipo de información puede ser solicitada al cliente, y/o qué información personal del cliente puede ser revelada en el informe, siempre en el supuesto del respeto e intimidad del cliente. El IPC incluye datos de la vida privada del paciente, por lo que sólo se incluirá la información necesaria para cumplir los objetivos terapéuticos (ver tabla 2 en anexo).

\section{Respetar y cumplir el derecho y el deber de informar al cliente}

De acuerdo con las normas dictadas en México (ver tabla 3 en anexo), el psicólogo tiene la obligación de brindar la información necesaria al paciente para que sea él quien tome decisiones acerca de su intervención psicológica, por lo que es necesario que llegue a acuerdos con el terapeuta. Asimismo, el psicólogo debe considerar que el paciente tiene derecho a la información obtenida de su tratamiento psicológico, así como el derecho de recibir un informe de alta con todos los documentos que lo acreditan, por lo que es necesario que el terapeuta sea preciso y utilice un lenguaje coherente y libre de tecnicismos. En los casos donde la naturaleza de la relación psicólogo-paciente impida proporcionar información, el terapeuta estará obligado a dar aclaraciones de los motivos de dicha situación. El psicólogo tiene la obligación de responder a las dudas que el paciente plantee acerca de su proceso de intervención.

\section{Organización de los contenidos del informe}

Una característica esencial de un IPC es que en éste se presenta la información recabada de manera estructurada y ordenada. La información vertida en el IPC describe las particularidades del caso, desde el nombre del terapeuta, datos específicos del paciente, datos del cliente, descripción de la demanda, objetivos de la evaluación, fechas, instrumentos de recolección de datos, procedimiento seguido, integración de resultados, conclusiones y recomendaciones, siempre en el entendido de respetar la identidad e integridad de los involucrados. Es de suma importancia mencionar que los datos descritos en el IPC serán presentados sólo con la información recabada a partir de instrumentos y procedimientos válidos para el área de la Psicología, con el objetivo de apoyar las afirmaciones indicadas en el informe (Fernández-Ballesteros, 2013; CNB, 2015) (ver tabla 4 en anexo).

\section{Descripción de los instrumentos utilizados y fa- cilitar la comprensión de los datos}

Cualquier evaluación y/o valoración psicológica en que se requiera el uso de instrumentos, el psicólogo está obligado a prestar atención a la estructura de éstos. El psicólogo debe estar bien informando acerca de su construcción, validez, consistencia, traducción, estandarización y adaptación a población mexicana. Asimismo, es necesario incluir la descripción detallada de cada instrumento utilizado, y no perder de vista que la evaluación se basará en múltiples pruebas como información complementaria para la interpretación de resultados. Por otro lado, el psicólogo nunca deberá basar sus decisiones en instrumentos obsoletos o no estandarizados (ver tabla 5 en anexo).

\section{Proceso de evaluación, hipótesis formuladas y justificación de conclusiones}

El IPC debe incluir una descripción pormenorizada del proceso de evaluación, esto es los diferentes momentos implicados en dicho proceso, desde la aplicación de pruebas psicológicas hasta la interpretación de éstas, todo con la finalidad de generar hipótesis de acción terapéutica con su justificación y evidencias de apoyo. También es indispensable que se tenga un orden específico al momento de redactar las conclusiones, siempre manteniendo una relación estrecha con los datos recolectados en las evaluaciones, los cuales sirven de evidencia para los juicios, interpretaciones y conclusiones plasmadas en el IPC. Esto debe permitir la contrastación y valoración de otros profesionales de la Psicología que en su caso convenga. Toda esta información debe ser correcta y confiable, de modo que permita al psicólogo formular un plan de intervención ad hoc a las necesidades de sus clientes (ver tabla 6 en anexo).

\section{Cuidar el estilo}

Al presentar un IPC - ya sea de manera oral o escrita - el psicólogo debe considerar el estilo de lenguaje que facilitará la comprensión de su informe. Primero se recomienda el uso de un lenguaje claro, sencillo y comprensible para el lector u oyente; el psicólogo tiene que asegurarse de que las palabras usadas significan lo que se quiere decir. Para ello debe utilizar palabras y oraciones breves y evitar tecnicismos, redundancias, etiquetas y ambigüedades. Las palabras y oraciones breves se comprenden con mayor facilidad; muchas veces el que redacta el IPC puede ser redundante; para evitar esta situación, se recomienda no recurrir a más palabras de las necesarias al sentido que se quiere dar al escrito. Después, para facilitar la comprensión de su informe se recomienda utilizar esquemas para organizar las ideas 
principales del informe, incluso el uso de ejemplos en caso necesario, logrando con ello mayor claridad a su comunicado (ver tabla 7 en anexo).

\section{Mantener la confidencialidad y la secrecía profesional}

En los primeros contactos que establece el psicólogo con el cliente, el profesional debe informarle de manera detallada acerca de su derecho a la confidencialidad; es así como el psicólogo, junto con el cliente, definirá el control y uso que se dará a la información que se obtenga por medio de su persona; el cliente autoriza de manera expresa los detalles de cómo y qué información puede ser revelada. La información que obtenga el psicólogo está resguardada con la secrecía profesional, y puede darse a conocer sólo si el cliente da su autorización explícita para hacerlo, y en su caso el cliente junto con el psicólogo definirán qué información y en qué condiciones podrá ser pública.

Por último, se darán a conocer al cliente los límites de esta confidencialidad; por ejemplo, en casos legales o en los que atenten contra su integridad física y moral. En casos extraordinarios el psicólogo puede negarse a proporcionar un informe cuando tiene la certeza de que se puede hacer un mal uso de la información vertida en el IPC (ver tabla 8 en anexo).

\section{Solicitar el consentimiento informado}

En los últimos años ha habido un crecimiento en la protección de los usuarios de los servicios de salud; así lo demuestran infinidad de documentos editados por diferentes autoridades relacionadas con dichos servicios. Como se ha comentado, es derecho del paciente mantenerse informado, por lo que el terapeuta deberá proporcionar al cliente el documento denominado "carta de consentimiento informado", así nombrado porque el cliente debe estar informado de los detalles del proceso terapéutico. El cliente deberá conocer, y en su caso aceptar, la información, usos y documentos que acompañarán su IPC. En general este documento se proporciona al cliente cuando se le han dado a conocer los detalles del trabajo psicológico por completo, incluyendo el inicio, fin, duración y los riesgos de éste, para que el cliente acepte la valoración y el tratamiento psicológico. En caso de existir incapacidad por parte del paciente para dar su consentimiento respecto al tratamiento psicológico, el profesional lo podrá obtener por medio de terceras personas (ver tabla 9 en anexo).

\section{Proteger los documentos}

Con la finalidad de proteger la información del paciente y evitar la interpretación inadecuada de la intervención psicológica, el terapeuta deberá abstenerse de compartir resultados e información a personas que no estén calificadas. De esta manera, todo IPC deberá resguardarse en condiciones óptimas de acuerdo con los lineamientos de las instituciones de salud y centros de atención; esto implica que se tenga en cuenta la seguridad, confidencialidad y el mantenimiento de los datos y expedientes del paciente. Es de especial interés mencionar aquellos relativos a la esfera íntima o también denominados sensibles, como el origen étnico, la preferencia sexual, las creencias religiosas y en particular el caso que nos ocupa el estado de salud. El psicólogo a cargo de las intervenciones del paciente tiene la responsabilidad de salvaguardar los datos, evaluaciones, resultados y todo lo contenido en la documentación clínica (ver tabla 10 en anexo).

Un análisis sintético de esta información mostró un total de 14 fuentes distintas y 222 numerales, artículos etc., que de una u otra forma hacen alusión a las recomendaciones señaladas. Así pues, en la Recomendación 3 que a la letra dice Respetar la dignidad, autonomía e intimidad del cliente, 10 fuentes (18 numerales o artículos), distintas mencionan estos aspectos. Las recomendaciones 8 y 9 que en su contenido refieren aspectos sobre la confidencialidad y el consentimiento informado respectivamente, siete fuentes diferentes los mencionan, sumando entre las dos un total de 53 numerales o artículos. Con relación a los aspectos de formato y contenido (recomendaciones 4,5 y 6), tan solo se encontraron cuatro documentos que refieren dichos elementos (ver tabla 11).

Es importante señalar que en las diez recomendaciones se entremezclan los documentos propuestos por alguna asociación de psicólogos, una entidad gubernamental, y un organismo internacional (ver tabla 11), lo que sugiere que las diez recomendaciones aluden a temáticas que de una u otra forma están consideradas por diferentes instancias reguladoras.

\section{ANÁLISIS Y DISCUSIÓN}

Como se recordará el objetivo de este trabajo es mostrar a los profesionales de la Psicología 10 recomendaciones básicas para la estructuración de un IPC; estas recomendaciones versan acerca de diferentes aspectos, desde los que mencionan el qué debe contener un IPC (formato, estilo y contenido) hasta referentes a cuestiones éticas, a manera de disposiciones. La definición de estas recomendaciones y los apoyos documentales mostrados en este trabajo representan una guía en donde se reúnen en un 
solo documento, lo que se encuentra de manera dispersa, si se tiene el propósito de adentrarse en el tema.

EI IPC es la culminación del proceso terapéutico; para escribir un reporte los psicólogos deben tener una serie de habilidades; por una parte, las relacionadas con el conocimiento de su estructura en términos de formato y contenido, y por otra las enmarcadas en una base conceptual de prácticas éticas. En cuanto al conocimiento de la estructura del IPC, y al ser éste un texto expositivo, el psicólogo deberá tener presente los conocimientos, las habilidades y las actitudes del lector, cuidando en todo momento la coherencia del texto. Al respecto, Pelco et al. (2009) recomiendan hacer un informe funcional o integrado, más que un informe como recurso informativo, porque estos últimos son más difíciles de comprender para las personas no especializadas, dado su énfasis en datos crudos, puntuaciones prueba tras prueba, resultados aislados e información muchas veces no referida al problema o queja principal del cliente, lo que dificulta la comunicación. Por su parte, los informes funcionales o integrados comunican todo lo que se evaluó y comprendió de una persona, y se caracterizan por tener una estructura referida a subtítulos, temáticas o etiquetas, lo que facilitan su comprensión, como habilidades académicas, funcionamiento emocional y recomendaciones, entre otras.

En un contexto universitario, y cuya prioridad es desarrollar habilidades para estructurar un informe integrado, Pelco et al. (2009) sugieren las siguientes estrategias: 1) énfasis sobre la naturaleza, estructura y características de los informes funcionales o integrados; 2) antes de presentar un IPC, programar ejercicios por medio de organizadores gráficos, en donde el estudiante plasme el caso en cuestión y pueda enlazar e integrar los diferentes dominios o aspectos evaluados; 3) uso de plantiIlas bien estructuradas, que a lo largo del tiempo se desvanecen para garantizar la generalización, y 4) discutir el caso y concluir con el mensaje central que se quiere comunicar, en términos de contenido. En este trabajo se presentan las indicaciones de Fernández-Ballesteros (2013) y Mancilla (2011), que aunadas a lo indicado por Pelco et al. (2009) se garantizaría un IPC de calidad. Pero estructurar un IPC de calidad involucra habilidades que se desarrollan con la práctica.

Respecto a las habilidades y conocimientos relativos a la bioética, como se habrá notado en este trabajo, seis de las 10 recomendaciones aluden a esta cuestión (1, 2, $3,8,9$ y 10), destacando las leyes, numerales y artículos que por mucho sobrepasan a los referidos a formato y contenido. En este caso particular de nuevo destaca la interrogante de cómo se pueden enseñar y aprender as- pectos como el respeto a la dignidad de la persona, a la libertad, a la autonomía, al consentimiento, a la confidencialidad de la información, etcétera; algunos dirán que de la misma manera en que se enseña y se aprende un formato, o sea leyendo manuales, analizando formatos, reconociendo su estructura, etcétera. Sin embargo, todos estos aspectos encierran la toma de decisiones frente a dilemas. Borda et al. (2002) sugiere, por una parte, y ante la necesidad de las carencias de los estudiantes respecto de los temas éticos, implementar una asignatura específica referente a la ética profesional, y por otra parte diseñar y probar estrategias que permitan a los estudiantes tener un sistema de valores sólido para reconocer dilemas éticos y generar soluciones de actuación en el mismo sentido.

Es importante destacar que el grupo de fuentes documentales referentes a la bioética, presentadas en este trabajo, son en su mayoría disposiciones gubernamentales nacionales. En México la fuente principal de información de bioética para los psicólogos, y aun cuando data de 2010, es el Código Ético de Psicólogo, desarrollado por la Sociedad Mexicana de Psicología (SMP); es común observar su referencia en algunas las asignaturas de los planes de estudio de las escuelas de Psicología en México, (Universidad Nacional Autónoma de México [UNAM], s/f); Universidad de Sonora [UNISON], s/f; Universidad de Guadalajara [UDG], s/f). De acuerdo con Ormart (2013), los códigos no tienen la fuerza de la ley, pero prescriben las conductas esperadas para los profesionales. Por otra parte, las disposiciones gubernamentales (algunas de ellas formalizadas como leyes, e instrumentadas por la Secretaría de Salud (SSA), por el Instituto Mexicano del Seguro Social (IMSS), o la Comisión Nacional de Bioética $(\mathrm{CNB})$, entre otras) también deben ser un referente obligado para los psicólogos mexicanos en formación, y para los ya consolidados, como reguladores de su actuar, incluido el desarrollo o estructuración de un IPC.

Otras fuentes incluidas en este trabajo, e igualmente referidas a las cuestiones de la bioética, son las propuestas de las asociaciones de psicólogos de otros países y de algunos organismos internacionales. La pregunta es: ¿Dónde radica su importancia para ser consideradas como un marco de referencia en la estructuración de un IPC? En primer término el código de ética de la American Psychological Association (2017) ha sido el modelo de inspiración para los códigos en más de un país mediante sus asociaciones; por ejemplo, España (Consejo General de Colegios Oficiales de Psicólogos, 2010; Fierro, 2001; Lindsay, 2009), México (Sociedad Mexicana de Psicología, 2010) y Argentina (Federación de Psicólogos de la República de Argentina, 2013), lo que sugiere semejanzas entre los códigos y un origen en común, aun cuando 
se podrán observar algunos matices en su contenido. Por otra parte, y sumado a lo anterior en el terreno del mundo globalizado, el código de ética de la American Psychological Association (2017) y las reglas del Ethics Committee of the American Psychological Association (American Psychological Association, 2018), son sin duda dos fuentes de información importantes en el ámbito de la bioética y la práctica profesional. Asimismo, el vínculo de la globalización con la educación superior ha permitido definir perfiles globalizados de los profesionales de la salud, acceso a materiales muy diversos, homogenización de planes de estudio y definir mercados laborales internacionales, de manera que es inminente conocer documentos reveladores más allá de las fronteras mexicanas (Altbach, 2016; UNESCO, 2019).

De este modo, si se quiere formar estudiantes competentes en la estructuración de IPC será necesario incluir en los planes de estudio tanto elementos de formato y contenido como de bioética, pero este último no como un contenido curricular extra, sino como parte de la práctica profesional y su regulación.

Por otra parte, al ser este trabajo una búsqueda no exhaustiva, un recuento final revela como limitación una probabilidad mediana de que se hayan quedado sin incluir fuentes tal vez importantes; sin embargo, están incluidas las más comúnmente citadas o consultadas por los especialistas.

Algunos lectores se preguntarán por qué algunas fuentes datan de cinco años o más, lo que parecería ser una crítica a la búsqueda plasmada en este trabajo; es evidente que las leyes, reglamentos, códigos y manuales no son actualizados con la frecuencia que los interesados en el tema quisieran, como una legislación debería ser evaluada y revisada, y en su caso modificada, de acuerdo con los avances en las herramientas de evaluación, los tratamientos, las mejoras en la prestación de los servicios, etcétera. Sin embargo, es difícil determinar la frecuencia con que un reglamento, legislación o código debe modificarse, como el Código Ético del Psicólogo de la Sociedad Mexicana de Psicología (2010); todo esto se complica cuando se piensa en la duración del proceso, su costo y la consulta a todos los implicados. Otra limitación se relaciona con la manera en que se efectuó la búsqueda de la información (consulta directa de páginas institucionales, organizaciones, manuales, etcétera); tal vez si se hubiera hecho por medio de bases de datos especializadas los resultados serían diferentes; esta es una cuestión que quizá se pueda responder si se plantea una nueva búsqueda.

Ahora bien, ¿hacia donde dirigir los esfuerzos para nuevas recomendaciones en la estructuración de un
IPC?; considérese la expresión de algunos colegas: "nuevas estrategias en el servicio psicológico, nuevas formas de hacer IPC"; está frase encierra un campo de actuación profesional denominado telepsicología, es decir, el servicio psicológico, mediado por las tecnologías de la información y la comunicación (TIC). En países como Estados Unidos, por medio de la American Psychological Association (2013), en España con el Consejo General de Psicología de España (2017), y en Puerto Rico con la Asociación de Psicología de Puerto Rico (comunicación personal, 3 de mayo de 2020), han desarrollado documentos extensos para la prescripción de servicios de evaluación y tratamiento psicológico en contextos clínicos a distancia, sin embargo, no hay indicios de que el IPC adquiera diferentes matices en ese sentido; ni siquiera se menciona. Es menester hacer un Ilamado de atención a las asociaciones de psicólogos en México para que se pongan a la vanguardia en este sentido.

Es evidente que la estructuración de un IPC de calidad no constituye un ente que se aprenda al inicio de la formación profesional, sino que se va moldeando a medida que la experiencia profesional va ascendiendo y surgen nuevos retos.

\section{Conclusiones}

Estructurar un IPC es una de tantas decisiones que debe tomar el psicólogo clínico en su haber profesional, proceso que va de los datos clínicos puros a las predicciones y recomendaciones. Un IPC puede ser una descripción general o una generalización descriptiva, es decir, por medio de pocas instancias se pueden derivar conclusiones o predicciones; en otros casos se tratará de una comprensión más amplia del individuo en un contexto específico. Sin embargo, lo cierto es que el psicólogo deber tener presentes todos los elementos vertidos a lo largo de este trabajo, elementos que le permitirán una mejor comunicación con otros especialistas, pero en particular bajo qué garantías y principios éticos desarrolla su actividad.

El psicólogo clínico debe asegurarse de que su informe se basa en datos sólidos; antes de iniciar su redacción debe asegurarse de que las pruebas que citará en dicho informe están respaldadas por investigaciones serias basadas en evidencias-, pero también debe informarse de los aspectos éticos que conlleva la redacción de un IPC; es necesario que el psicólogo clínico se mantenga al día respecto a las reglas, guías, leyes, etcétera, que protegen la integridad de los pacientes, así como los aspectos formales en la redacción de los IPC. 


\section{Referencias}

Altbach, P. (2016). Globalization and the university: realities in an unequal world. In P. Altbach. Global perspectives on higher education. Baltimore: Johns Hopkins University Press. https://doi.org/10.1111/hequ.12117

American Psychological Association (APA) (2013). Guidelines for the practice of telepsychology. American Psychologist, 68(9), 791-800. http://dx.doi.org/10.1037/a0035001

American Psychological Association (APA) (2017). Ethical principles of psychologists and code of conduct, Amendments January 1, 2017. Recuperado de https:// www.apa.org/ethics/code/ethics-code-2017.pdf

American Psychological Association (APA) (2018). Ethics Committee of the American Psychological Association. Recuperado de https://www.apa.org/ethics/committeerules-procedures-2018.pdf

Arslan, R. (2018). A review on ethical issues and rules in psychological assessment. Journal of Family Counsulting, and Education, 3(1), 17-29. https://doi.org/10.32568/jfce.310629

Borda, M., Del Río, C., Pérez, A., \& Martín, A. (2002). ¿Conocen los estudiantes de Psicología los principios éticos básicos para actuar como terapeutas? Propuesta de una innovación en la docencia universitaria. Revista de Enseñanza Universitaria, 19, 15-34.

Bustos, V. (2018). Informe psicológico clínico: Definición y precisiones. Boletines COLPSIC, 36, 6-10.

Cattáneo, B. (2007). Informe psicológico: Su elaboración y características en diferentes ámbitos. Argentina: Editorial Universitaria de Buenos Aires.

Comisión Nacional de Bioética (CNB) (2015). Guía Nacional para la Integración y el Funcionamiento de los Comités Hospitalarios de Bioética. Secretaría de Salud. Recuperado de http://www.conbioetica-mexico.salud.gob. mx/descargas/pdf/registrocomites/Guia_CHB Final_ Paginada con forros.pdf

Consejo General de Colegios Oficiales de Psicólogos (CGCOP) (2010). Código deontológico del psicólogo. Recuperado de https://www.cop.es/pdf/Codigo-Deontologico-ConsejoAdaptacion-Ley-Omnibus.pdf

Consejo General de la Psicología de España (CGPE) (2017). Guía para la práctica de TelePsicología. Recuperado de http:// www.cop.es/pdf/telepsicologia2017.pdf

Cristaldo, M. R. (2012). La práctica de la ética profesional: ¿Fácil de enseñar, difícil de aplicar? Erureka, 9(2), 228-232.

Díaz-Barriga, F., Pérez, M., \& Lara, Y. (2016). Para enseñar ética profesional no basta con una asignatura: Los estudiantes de Psicología reportan incidentes críticos en aulas y escenarios reales. Revista Iberoamericana de Educación Superior, VII(18), 42-58. https://doi.org/10.22201/ iisue.20072872e.2016.18.175

Erikson, A., \& Maurex, L. (2018). Teaching the writing of psychological reports through formative assessment: Peer and teacher review. Assessment \& Evaluation in Higher Education, 43(8), 1294-1301. https://doi.org/10.1 080/02602938.2018.1459470

Federación de Psicólogos de la República Argentina (FPRA) (2013). Código de ética. Recuperado de http://fepra.org.
ar/docs/C ETICA.pdf

Fernández-Ballesteros, R. (2013). Comunicación de los resultados: El informe psicológico. En R. FernándezBallesteros. Evaluación psicológica. Conceptos, métodos y estudio de casos. Madrid: Pirámide.

Fernández-Ballesteros, R., \& Calero, M. D. (2013). Garantías científicas y éticas de la evaluación psicológica. En R. Fernández-Ballesteros. Evaluación psicológica. Conceptos, métodos y estudio de casos. Madrid: Pirámide.

Fierro, A. (2001). Génesis y análisis el código deontológico. Papeles del Psicólogo, 78 Recuperado de http://www. papelesdelpsicologo.es/resumen?pii=851

Fraile, A. (2006). El sistema Universitario europeo como modelo posible para la educación superior latinoamericana. Revista Electrónica de Investigación Educativa, 8(1).

Groth-Marnat, G., \& Horvarth, L. (2006). The psychological report: A review of current controversies. Journal Clinical Psychology, 62(1), 73-81. https://doi.org/10.1002/ jclp. 20201

Heredia, C., Santaella, G., \& Somarriba, L. (2012). Informe psicológico. Facultad de Psicología, UNAM. Recuperado de http://www.psicologia.unam.mx/documentos/pdf/ publicaciones/Informe Psicologico Heredia y Ancona Santaella Hidalgo Somarriba Rocha TAD 7 sem.pdf

Instituto Mexicano del Seguro Social (IMSS) (2020). Norma que establece las disposiciones técnico-médicas para la atención de pacientes con trastornos mentales y del comportamiento. Coordinación de Modernización y Competitividad del IMSS. Recuperado de http://reposipot.imss.gob.mx/normatividad/DNMR/ Norma/2000-001-010.pdf

Ley de Salud Mental del Distrito Federal (2011). Decreto de la Asamblea Legislativa del Distrito Federal. Gaceta Oficial del Distrito Federal. Recuperado de http://cgservicios. df.gob.mx/prontuario/vigente/r410203.htm

Ley federal de protección de datos personales en posesión de sujetos obligados de la CDMX (2018). INFOCDMX. Gaceta Oficial de la Ciudad de México, 10 de abril de 2018. Recuperado de http://www.infodf.org.mx/ documentospdf/Ley_datos_CDMX_web.pdf

Ley federal de transparencia y acceso a la información pública (2016). Decreto Cámara de Diputados del H. del Congreso de la Unión de los Estados Unidos Mexicanos. Diario Oficial de la Federación. Recuperado de http://www. diputados.gob.mx/LeyesBiblio/pdf/LFTAIP_270117.pdf

Ley General de Salud (2021). Decreto Cámara de Diputados del $\mathrm{H}$. del Congreso de la Unión de los Estados Unidos Mexicanos. Diario Oficial de la Federación. Recuperado de $\quad$ http://www.diputados.gob.mx/LeyesBiblio/ $\mathrm{pdf} / 142$ 190221.pdf

Lindsay, G. (2009). Ética profesional y psicología. Papeles del Psicólogo, 30(3), 184-194.

Mancilla, B. E.(2011). Manual para elaborar informes psicológicos clínicos. México: Facultad de Psicología, UNAM.

Ochoa, E. (2018). Competencia ética en profesionistas de la Psicología: Un estudio descriptivo. Éthique et Sante, 4, 4257. https://doi.org/10.25965/trahs.1283

Organización de las Naciones Unidas para la Educación, la Ciencia y la Cultura (UNESCO) (2019). Convenio mundial 
sobre el reconocimiento de las cualificaciones relativas a la educación superior. Recuperado de https://es.unesco. org/news/unesco-adopta-primer-tratado-internacionalnaciones-unidas-educacion-superior

Organización Mundial de la Salud (OMS) (2003). Legislación sobre salud mental y derechos humanos. Recuperado de https://www.who.int/topics/human rights/Legislacion salud mental DH.pdf

Organización Mundial de la Salud (OMS) (2017). Pautas de la OMS sobre la ética sobre la vigilancia de la salud pública. Recuperado de https://iris.paho.org/bitstream/ handle/10665.2/34499/9789275319840-spa. pdf? sequence $=6$

Ormart, E. (2013). El secreto profesional en psicología: Aspectos deontológicos, legales y éticos. Psicología para América Latina, 24, 191-205.

Pasmanik, D., \& Winkler, M. I. (2009). Buscando orientaciones: Pautas para la enseñanza de la ética profesional en Psicología en un contexto con impronta posmoderna, PSYKHE, 18(2), 37-49. http://dx.doi.org/10.4067/S071822282009000200003

Pelco, L., Ward, S., Coleman, L., \& Young, J. (2009). Teacher rating of three psychological report styles. Training and Education in Professional Psychology, 3(1), 19-27. https:// doi.org/10.1037/1931-3918.3.1.19

Pérez, E., Muñoz, M., \& Ausín, B. (2003). Diez claves para la elaboración de informes psicológicos clínicos (de acuerdo con las principales leyes, estándares, normas y guías actuales). Papeles del Psicólogo, 24(86), 48-60.

Secretaría de Salud (SSA) (2012). Norma Oficial Mexicana NOM004.SSA3-2012, Del expediente clínico. Diario Oficial de la Federación. Recuperado de http://dof.gob.mx/nota detalle_popup.php?codigo $=5272787$

Secretaría de Salud (SSA) (2014). Norma Oficial Mexicana NOM-025-SSA2-2014, para la prestación de servicios de salud en unidades de atención integral hospitalaria médico-psiquiátricas. Diario Oficial de la Federación. Recuperado de http://www.dof.gob.mx/nota_detalle. php?codigo $=5406383 \&$ fecha $=04 / 09 / 2015$

Sociedad Mexicana de Psicología (SMP) (2010). Código Ético del Psicólogo. México: Trillas.

Universidad de Guadalajara (UDG) (s. f.). Licenciatura en Psicología. Recuperado de http://guiadecarreras.udg.mx/ licenciatura-en-psicologia/\#tabla1

Universidad de Sonora (Unison) (s. f.). Plan de Estudios Psicología de la salud. Recuperado de https://biologicascajeme. unison.mx/wp-content/uploads/2019/10/ PlandeEstudios-LPS-2112.pdf

Universidad Nacional Autónoma de México (UNAM) (s. f.). Facultad de Psicología. Recuperado de http://oferta.unam. $\mathrm{mx} /$ planestudios/psicologia-fpsicologia-planestudios 17.pdf

Wiener, J., \& Costaris, L. (2012). Teaching psychological report writing content a process. Canadian Journal of School Psychology, 27(2), 119-135. https://doi. org/10.1177/0829573511418484 


\section{AnEXo}

Tabla 1.

Documentos de apoyo relativos a la cualificación del evaluador.

\section{FUENTE} Artículo/NUMERAL

Artículo 1. Los servicios, la enseñanza y la investigación que realiza el psicólogo se basan necesariamente en un cuerpo de conocimientos válido y confiable, sustentado en la investigación científica, por lo que el trabajo que desempeña debe corresponder directamente con la educación, formación, experiencia supervisada o experiencia profesional que haya recibido formalmente.

Artículo 4 . El psicólogo se mantendrá razonablemente actualizado acerca de la información científica y profesional actual en su campo de actividad y realizar esfuerzos continuos para mantener su competencia y pericia en las habilidades que emplea. Recibirá educación, formación supervisión y consulta adecuadas.

Artículo 6. El psicólogo presenta como cualificaciones o credenciales de su trabajo psicológico, sólo los grados que: 1) haya obtenido de una institución educativa acreditada, o 2) sean la base de la licencia en psicología por parte del Estado en el que practique.

Artículo 9. El psicólogo reconoce que sus problemas y conflictos pueden interferir con su efectividad. Por lo tanto, se abstendrá de llevar a cabo una actividad cuando sabe o debía saber que sus problemas personales probablemente

SMP dañen a un paciente, cliente, colega, estudiante, participante en investigación u otra persona con quien tenga una (2010). $\quad$ dañen a un paciente, cliente, coleg

Artículo 11. Cuando el psicólogo se percata de problemas personales que puedan interferir con el desempeño adecuado de los deberes relativos a su trabajo, toma medidas apropiadas, tales como obtener asesoría, ayuda profesional, y determina si debe limitar, suspender o terminar dichos deberes.

Artículo 30. El psicólogo efectúa solamente las intervenciones para las cuales posee la educación, formación o experiencia supervisada, y la pericia necesaria.

Artículo 35. El psicólogo que utiliza técnicas o procedimientos de intervención psicológica a distancia, por ejemplo la internet o el teléfono, se cerciora de recibir la educación y formación necesaria para:

a) prescindir de señales auditivas (como amplitud de voz, extensión del discurso, tartamudeo y vacilación al hablar) y señales visuales (como contacto visual, ruborización e inquietud) propias de la interacción frente a frente, y b) trabajar solamente con señales textuales.

Artículo 51. Los usuarios tendrán derecho a obtener prestaciones de salud oportunas y de calidad idónea y a recibir atención profesional y éticamente responsable, así como trato respetuoso y digno de los profesionales y técnicos auxiliares.

Ley Artículo 79. Para el ejercicio de actividades profesionales en el campo de la medicina, odontología, veterinaria, biología,

General

de Salud

(2021). bacteriología, enfermería, trabajo social, química, psicología, ingeniería sanitaria, nutrición, dietología, patología y sus ramas, y las demás que establezcan otras disposiciones legales aplicables, se requiere que los títulos profesionales o certificados de especialización hayan sido legalmente expedidos y registrados por las autoridades educativas competentes.

APA

(2017).

2.03. Mantener la competencia. Los psicólogos realizan esfuerzos permanentes para desarrollar y mantener su competencia.

2.04. Fundamentos para los juicios científicos y profesionales. El trabajo de los psicólogos se basa en el conocimiento científico y profesional establecido por la disciplina.

Fernández-

Ballesteros

(2013).

66. Si se requiere intervención y el evaluador no está cualificado para llevarla a cabo, el sujeto será remitido al profesional más adecuado.

Artículo 7. El profesional de salud mental tiene la obligación de estar debidamente acreditado para ejercer sus funciones, lo que incluye al menos tener a la vista Cédula Profesional, Título Profesional y, en su caso, certificados de especialización expedidos y registrados por las autoridades educativas competentes, con la finalidad de que el usuario corrobore que es un especialista en la materia de salud mental.

Ley de

Salud

Mental del

Artículo 24. La evaluación y el diagnóstico psicológico deberán realizarse por psicólogos certificados en instituciones públicas y privadas que realicen dicha actividad, para lo cual deberán cumplir con lineamientos y estándares emitidos por organismos internacionales y nacionales en materia de salud mental, así como la Ley General de Salud y las Normas Oficiales respectivas. El psicólogo que realice la evaluación y el diagnóstico a los que se refiere el presente

Distrito

Federal

(2011). artículo debe contar con el reconocimiento y la capacitación adecuada por un cuerpo colegiado, con la finalidad de garantizar que conoce las limitaciones de los instrumentos y la aplicación de un procedimiento de esta naturaleza en sus distintas variedades. Asimismo, para la emisión de dictámenes solicitados por las autoridades, deberá acreditar la especialidad de perito en psicología forense, expedido por institución con validez oficial.

Artículo 25. El psicoterapeuta debe ser psicólogo con cédula profesional y con estudios de postgrado en psicoterapia, realizados en instituciones que cuenten con validez oficial. 
Tabla 2.

Documentos de apoyo relativos a la dignidad, libertad, autonomía e intimidad del cliente.

\section{Fuente Artículo/numeral}

Artículo 14. El psicólogo que trabaja con las etnias de México o con extranjeros se mantiene alerta de prejuicios y mal interpretaciones dadas por diferencias en idioma y cultura, y considera, al emitir sus juicios, las limitaciones derivadas del empleo de traductores y otros terceros, cuando es el caso. Deja saber a las personas usuarias de su servicio los límites a la confidencialidad en tales circunstancias. Procurará que los terceros en los que se apoye sean personas fiables.

Artículo 90. En las actividades relativas a su trabajo, el psicólogo respeta los derechos que otros tienen para sustentar valores, cultura, actitudes y opiniones diferentes a los suyos. Asimismo, no discrimina injustamente a partir de edad, género, raza, origen étnico, idioma, nacionalidad, religión, orientación sexual, minusvalía, nivel socioeconómico o cualquier criterio proscrito por la ley.

Artículo 91. Cuando las diferencias de edad, género, raza, origen étnico, nacionalidad, religión, orientación sexual, minusvalía, idioma o nivel socioeconómico afectan significativamente su trabajo respecto a ciertos individuos o grupos, el psicólogo adquiere la formación, experiencia, asesoría y supervisión necesarias para asegurar la competencia de sus servicios, o canaliza a los usuarios de manera adecuada.

Artículo 92. El psicólogo no incurre, a sabiendas, en conducta que hostigue, acose o devalúe a personas con quienes interactúe en su trabajo, basándose en factores tales como la edad, el género, la raza, el origen étnico, la nacionalidad, la religión, la orientación sexual, la minusvalía, el idioma o el nivel socioeconómico de esas personas.

Artículo 118. El psicólogo obtiene consentimiento informado apropiado a la terapia, investigación u otros procedimientos, utilizando un lenguaje entendible para los participantes. El contenido del consentimiento informado variará dependiendo de muchas circunstancias; sin embargo, generalmente supone que la persona:

SMP 1. posee la capacidad para consentir,

(2010). 2. $\quad$ 2. se le ha proporcionado la información significativa concerniente al procedimiento,

3. ha expresado libremente y sin influencias indebidas su consentimiento, y

4. el consentimiento se ha documentado en forma apropiada.

Artículo 120. El psicólogo explica a las personas legalmente incapaces de consentir informadamente acerca de las intervenciones propuestas de manera conmensurable a las capacidades psicológicas de estas personas, considerando sus preferencias e intereses.

Artículo 132. El psicólogo tiene la obligación básica de respetar los derechos a la confidencialidad de aquellos con quienes trabaja o le consultan, reconociendo que la confidencialidad puede establecerse por ley, por reglas institucionales o profesionales, o por relaciones científicas, y toma las precauciones razonables para tal efecto.

Artículo 133. Con el fin de minimizar intrusiones en la privacía el psicólogo sólo incluye en sus informes escritos u orales, consultorías o asesorías y similares, aquella información pertinente al propósito de dicha comunicación.

Artículo 138. El psicólogo discute con las personas y organizaciones con quienes establece una relación científica o profesional (incluyendo, hasta donde sea posible, menores y sus representantes legales):

1. Ios límites relevantes de la confidencialidad, incluyendo los aplicables a la terapia de grupo, conyugal o familiar, o a la consultoría o asesoría organizacional y,

2. los usos previsibles de la información generada por sus servicios.

A menos que no sea factible o está contraindicado, la discusión sobre confidencialidad se hará al principio de la relación y durante ésta, conforme lo hagan necesario nuevas circunstancias.

Normatividad. Las acciones de salud se encuentran reguladas por normas nacionales e internacionales que se sustentan en normas éticas que proveen una estructura para realizar análisis y tomar decisiones. En ellas se enfatiza que el personal de salud debe proteger la dignidad, los derechos, la seguridad y el bienestar de los pacientes. Se establecen también pautas para evaluar y equilibrar los beneficios y riesgos de las intervenciones, con énfasis en el deber de maximizar los beneficios sobre los riesgos.

Carta de los Derechos Generales de las Pacientes y los Pacientes: Fue elaborada por la CONAMED en el año de 2001. Este decálogo destaca la importancia del respeto a los derechos de los pacientes, el respeto a su dignidad y autonomía, así como la necesidad de garantizar la confidencialidad de la información generada en la relación médico-paciente.

Principio E: Respeto por los derechos y la dignidad de las personas. Los psicólogos respetan la dignidad y el valor de todas las personas y el derecho a la privacidad, a la confidencialidad y a la autodeterminación de los individuos. Los psicólogos tienen conocimiento de que puede ser necesario proteger los derechos y el bienestar de las personas y las comunidades cuya vulnerabilidad afecte la toma de decisiones de manera autónoma. Los psicólogos conocen y respetan las diferencias de roles, culturales e individuales, incluso las relacionadas con la edad, el género, la raza, el origen étnico, la cultura, la nacionalidad, la religión, la identidad u orientación sexual, la discapacidad, el idioma y el

$\begin{array}{ll}\text { APA } & \text { nivel socioeconómico, y consideran estos factores al trabajar con miembros de estos grupos. Los psicólogos intentan } \\ \text { (2017). } & \text { eliminar el efecto que pueda producir en su trabajo cualquier tipo de prejuicio basado en estos factores y no participan }\end{array}$ ni permiten actividades de terceros basadas en dichos prejuicios a sabiendas.

4.04. Minimización de las intrusiones a la privacidad.

(a) Los psicólogos incluyen en sus consultas e informes orales y escritos únicamente la información relativa al propósito para el que la comunicación ha sido realizada.

(b) Los psicólogos discuten la información confidencial obtenida en su trabajo únicamente con fines científicos o profesionales apropiados y exclusivamente con personas claramente involucradas en tales asuntos. 
9. Derechos humanos y de respeto a la dignidad de las personas usuarias. Dentro de cada unidad de atención integral hospitalaria médico-psiquiátrica, las personas usuarias tienen derecho a:

9.1. Recibir un trato digno y humano por parte del personal de las unidades de atención integral médico-psiquiátrica SSA independientemente de su diagnóstico, origen étnico, sexo, edad, ideología, condición de salud, social o económica, (2014). religión, preferencia sexual, estado civil o cualquier otra condición de persona, de acuerdo con lo señalado en las disposiciones jurídicas nacionales e internacionales aplicables en nuestro país.

9.2. No ser objeto de discriminación por su condición mental, ni ser objeto de diagnósticos o tratamientos por razones políticas, sociales, raciales, religiosas u otros motivos distintos o ajenos al estado de su salud mental.

Ley $\quad$ Artículo 74 Bis. La persona con trastornos mentales y del comportamiento tendrá los siguientes derechos:

General $\quad 1 . \quad$ Derecho a la mejor atención disponible en materia de salud mental y acorde con sus antecedentes culturales, lo

de Salud que incluye el trato sin discriminación y con respeto a la dignidad de la persona, en establecimientos de la red del Sistema (2021). Nacional de Salud.

OMS Pauta 9. La vigilancia de las personas o grupos particularmente susceptibles a enfermedades, daños o injusticias es (2017). fundamental y exige un escrutinio cuidadoso para evitar la imposición de cargas adicionales innecesarias.

\section{Tabla 3.}

Documentos de apoyo relativos al respeto y cumplimiento del derecho y deber de informar al cliente.

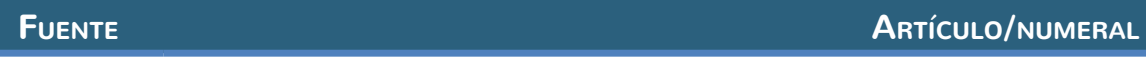

Artículo 109. El psicólogo tiene la obligación de informar de los posibles riesgos a los usuarios o terceros que reciban servicios psicológicos de personas no profesionales de esta disciplina. Asimismo, llama la atención de las instancias legales, encargadas del otorgamiento de la licencia para ejercer la Psicología cerca de estas personas, para que procedan según corresponda.

Artículo 50. Cuando el psicólogo hace valoraciones, evaluaciones; o proporciona tratamiento, consejo, supervisión, consultoría, investigación u otros servicios dirigidos a individuos, grupos, comunidades u organizaciones, lo hace utilizando un lenguaje razonablemente entendible para el receptor de sus servicios o actuación, proporcionando de antemano información apropiada acerca de la naturaleza de tales actividades y posteriormente sobre los resultados y conclusiones. Si la ley o los roles organizacionales impiden que el psicólogo proporcione tal información a individuos SMP particulares o grupos, podrá hacerlo al término del servicio.

(2010) Artículo 51. El psicólogo se asegura de que se proporcione una explicación de los resultados utilizando un lenguaje entendible para la persona valorada o para otras personas autorizadas legalmente para actuar en favor de ésta. Independientemente de que las calificaciones e interpretación las realice el psicólogo, un ayudante, por medios automáticos u otros servicios externos, sólo el psicólogo puede tomar las medidas razonables para asegurar que se den las explicaciones apropiadas de los resultados. En los casos en los que la naturaleza de la relación impida dar estas explicaciones a la persona evaluada o personas autorizadas para recibirlas (como ocurre en algunos casos de selección o consultoría organizacional, preempleo o selección de elementos de seguridad, y evaluaciones y peritajes judiciales o forenses), el psicólogo aclarará con antelación que no proporcionará tales explicaciones.

Artículo 72. El psicólogo hace esfuerzos razonables para contestar las preguntas de los usuarios de sus servicios y evita malentendidos aparentes acerca de los servicios que ofrece. Siempre que sea posible, el psicólogo proporciona información oral y/o escrita, utilizando un lenguaje entendible para el usuario de sus servicios.

5.6. Los profesionales de la salud están obligados a proporcionar información verbal al paciente, a quien ejerza la SSA patria potestad, la tutela, representante legal, familiares o autoridades competentes. Cuando se requiera un resumen (2012). clínico u otras constancias del expediente clínico, deberá ser solicitado por escrito. Son autoridades competentes para solicitar los expedientes clínicos las autoridades judiciales, órganos de procuración de justicia y autoridades administrativas.

9.10. Explicación de los resultados de la evaluación. Sin importar si la tabulación y la interpretación son realizadas por los psicólogos, por empleados o asistentes, o por servicios automatizados u otros, los psicólogos toman las medidas

APA

(2017). razonables para asegurar que el individuo o el representante designado obtenga las explicaciones de los resultados, a menos que la naturaleza de la relación impida proporcionarla (tales como en algunas consultas institucionales, exploraciones pre-ocupacionales o de seguridad y evaluaciones forenses) y este hecho haya sido claramente explicado previamente a la persona evaluada.

63. El evaluador discutirá con el cliente o sujeto las diferentes secciones del informe.

Fernández- 64. El evaluador tratará con el cliente, sujeto u otras personas implicadas en la evaluación las posibles Ballesteros recomendaciones, asegurándose de que las entienden.

(2013). 65. El evaluador reflejará en el informe las cuestiones surgidas durante la información de resultados y de recomendaciones, en la versión final de éste.

\section{Ley}

General

de Salud

(2021).
III. Derecho al consentimiento informado de la persona o su representante, en relación al tratamiento a recibir. Artículo 77 BIS 37. Los beneficiarios del Sistema de Protección Social en Salud tendrán además de los derechos establecidos en el artículo anterior, los siguientes:

$\checkmark$. Recibir información suficiente, clara, oportuna y veraz, así como la orientación que sea necesaria respecto de la atención de su salud y sobre los riesgos y alternativas de los procedimientos diagnósticos, terapéuticos y quirúrgicos que se le indiquen o apliquen. 
Derecho a la información: Consiste en que la información debe de ser clara, veraz, suficiente, oportuna y objetiva CNB acerca de todo lo relativo al proceso de atención, principalmente del diagnóstico, tratamiento y pronóstico

(2015). del padecimiento de la persona. Previo a la realización de cualquier procedimiento, también se debe informar adecuadamente acerca de los riesgos, beneficios (físicos o emocionales) y de la duración del mismo, así como de otras alternativas, si las hubiera.

SSA

9.9. Recibir información veraz, concreta, respetuosa y en lenguaje comprensible para las personas usuarias y para su

(2014). representante legal, en relación con el diagnóstico médico, así como respecto de sus derechos y del tratamiento que se pretenda aplicar.

Ley de

Salud

Mental del

Distrito

Federal

(2011).

Artículo 32. El psicólogo debe proporcionar información clara y precisa a la persona usuaria y a sus familiares respecto al tratamiento que se pretenda emplear a las personas, el cual no podrá iniciarse sin antes haber sido exhaustivos en proporcionar la información al respecto, así como haber sido aceptadas las responsabilidades y compromisos que implican la aplicación del tratamiento.

IMSS
(2020).

7.2.3.24. La dirección de la unidad hospitalaria psiquiátrica, a solicitud escrita del paciente, familiar, tutor o representante legal, proporcionará un resumen clínico sobre el diagnóstico, evolución, tratamiento y pronóstico del padecimiento.

OMS

(2017).

Pauta 13. Los resultados de la vigilancia deben comunicarse efectivamente al público objetivo relevante.

\section{Tabla 4.}

Documentos de apoyo relativos a la organización de contenidos del informe.

44. La forma de presentar el informe (oral, escrita o ambas) será la apropiada.

45. El informe incluirá un resumen con las conclusiones más importantes.

46. El informe señalará quién es el autor, el cliente y el sujeto, así como a quién se presentará o enviará.

47. Los datos se presentan de acuerdo con las fuentes de información, instrumentos y procedimientos utilizados.

48. Los datos se estructurarán siguiendo criterios psicológicos y se situarán en la parte de resultados que habrá en el informe.

Fernández- 49. Los asuntos que sobrepasan las demandas iniciales no se ignorarán, aunque sí serán considerados aparte.

Ballesteros

(2013).

50. El informe responderá a las demandas del cliente con recomendaciones apropiadas.

51. Las demandas del cliente nunca deberán quedar sin abordarse.

52. Las fuentes de información, los instrumentos y tests utilizados quedarán reflejados con el suficiente detalle.

53. El informe detallará los pasos y procedimientos utilizados para responder a las demandas del cliente.

54. La sección del informe destinada a exponer los resultados reflejará el peso dado a la información obtenida y la forma en que se ha integrado.

55. En la sección del informe sobre los resultados, cada afirmación psicológica será expresamente basada en los datos recogidos y valorada en función de su importancia con respecto a las demandas del cliente.

56. Las inconsistencias encontradas entre los datos se discutirán en la sección sobre resultados.

El informe psicológico incluye:

1.Ficha de identificación.

2.Motivo de consulta.

3.Pruebas aplicadas.

4. Descripción del paciente.

5.Antecedentes: Familiograma, personales, patológicos, heredofamiliares, educacionales, hábitos.

6 . Evolución del padecimiento y estado actual, dinámica familiar, conducta, eventos importantes (último año).

Resultados:

7.Área intelectual.

8.Área percepto-motora.

Mancilla 9.Área afectiva o personalidad. Ésta incluye:

(2011). - Tono afectivo.

- Forma de demandar y expresar el afecto.

- Características de control de impulsos.

-Relaciones interpersonales.

-Autoconcepto.

- Capacidad de insight y sus características.

- Mecanismos de defensa.

10.Áreas libres de conflictos.

11.Diagnóstico.

12.Pronóstico (eje IV y eje V del DSM).

13. Tratamiento: Recomendaciones. 
CNB Integración. Los profesionales de la salud clarifican los datos clínicos del caso, como el diagnóstico, el pronóstico y

(2015). las alternativas de tratamiento. Éste debe ser considerado como el paso previo a todo análisis bioético.

7.2.3.16. Todas las personas con trastornos mentales y del comportamiento atendidas en los servicios de consulta externa y hospitalización deberán contar con un expediente clínico, integrado por todos los apartados establecidos en IMSS la normatividad institucional y sectorial vigente.

(2020). 7.2.3.17. Todo el personal de salud que dé atención al paciente con trastorno mental y del comportamiento deberá registrar los procedimientos de atención al paciente de conformidad con lo establecido en la NOM 004-SSA3-2012 del Expediente Clínico y demás normatividad institucional y sectorial vigente.

Tabla 5.

Documentos de apoyo relativos a la descripción de instrumentos de evaluación utilizados.

Artículo 109. El psicólogo tiene la obligación de informar de los posibles riesgos a los usuarios o terceros que reciban Artículo 15. El psicólogo que construye, desarrolla, adapta, administra, o usa técnicas de valoración psicológica, entrevistas, pruebas, cuestionarios, u otros instrumentos, y/o los califica, o interpreta, con fines clínicos, educativos, de selección de personal, organizacionales, forenses, de investigación u otros, lo hace en forma y con propósito apropiados a la luz de los datos de investigación y de la utilidad y la aplicación apropiadas de las técnicas. Es decir, las valoraciones, recomendaciones, informes, y diagnóstico psicológico o enunciados evaluativos del psicólogo se basan estrictamente en información y técnicas (incluyendo entrevistas personales al individuo cuando es apropiado) suficientes y actuales para proporcionar sustento a sus interpretaciones y recomendaciones.

Artículo 16. El psicólogo que desarrolla y conduce investigación con pruebas y otras técnicas de valoración utiliza procedimientos científicos y conocimiento profesional actualizados para su diseño estandarización, validación, reducción o eliminación de sesgos y recomendaciones de uso.

Artículo 17. El psicólogo que administra, califica, interpreta, o usa técnicas de valoración se cerciora de que éstas se basen en datos sólidos que garanticen la confiabilidad, validez, y normas, así como la aplicación apropiada y usos de las técnicas y/o instrumentos que emplea.

Artículo 18. El psicólogo identifica situaciones en las que ciertas técnicas de valoración o normas no son aplicables o requieren de ajustes para su administración o interpretación. Debido a factores tales como el género, la edad, la raza, el origen étnico, el origen nacional, la orientación sexual, la minusvalía, el idioma, o el nivel socioeconómico de los individuos o grupos, no emplea técnicas o instrumentos solamente traducidos de otro idioma y/o cuyos datos acerca de su construcción, adaptación, validez, confiabilidad, estandarización y/o investigación de resultados se hayan determinado con base en estudios realizados en poblaciones diferentes a la que pertenezcan los individuos o grupos que pretenda valorar.

Artículo 20. Al interpretar resultados de valoración, incluyendo interpretaciones automatizadas, el psicólogo toma en cuenta los diversos factores de la prueba u otro instrumento de medida, y las características de la persona valorada que pudiesen afectar su juicio o reducir la precisión de las interpretaciones. Indica cualquier reserva significativa que tenga acerca de la precisión o las limitaciones de las interpretaciones.

Artículo 22. El psicólogo no basa sus decisiones de valoración o intervención o sus recomendaciones, en datos, normas o resultados de pruebas psicológicas obsoletos para propósito actuales. De manera similar, no basa tales decisiones o recomendaciones en pruebas psicológicas o medidas inútiles o construidas con otros propósitos.

Artículo 24. El psicólogo que ofrece valoración o procedimientos de calificación a otros profesionales describe con precisión el propósito, las normas, la validez, la confiabilidad, y las aplicaciones de los procedimientos, así como cualquier característica especial aplicable a su uso. El psicólogo selecciona servicios de calificación e interpretación (incluyendo servicios automatizados) apegados estrictamente a las normas de calidad científica que garanticen la validez y confiabilidad del programa y procedimientos. Se cerciora que tales programas y procedimientos tengan como base estudios que se hubiesen realizado en las poblaciones a las que pertenezcan los individuos bajo valoración; asimismo dará su opinión con base en otras consideraciones pertinentes.

Artículo 25 . El psicólogo asume la responsabilidad por la aplicación, interpretación y uso de instrumentos de valoración apropiados, ya sea que él mismo califique e interprete los resultados, o que emplee servicios automatizados o de otra índole.

\subsection{Uso de las evaluaciones.}

(a) Los psicólogos administran, adaptan, califican, interpretan o utilizan técnicas de evaluación, entrevistas, tests o instrumentos, de manera y con propósitos apropiados a la luz de la investigación o de la manifiesta utilidad y aplicación apropiada de las técnicas.

(b) Los psicólogos utilizan instrumentos de evaluación cuya validez y confiabilidad hayan sido establecidas para su aplicación en la población objeto de los tests. Cuando tal validez o confiabilidad no haya sido establecida, los

APA psicólogos describen la efectividad y limitaciones de los resultados y la interpretación de los tests.

(2017). $\quad$ (c) Los psicólogos utilizan métodos de evaluación apropiados para el idioma de preferencia y la competencia del individuo, a menos que el uso de un lenguaje alternativo sea pertinente para los temas de la evaluación.

9.08. Tests obsoletos y resultados desactualizados de tests.

(a) Los psicólogos no basan sus decisiones de evaluación o de intervención ni sus recomendaciones, en datos o resultados de tests desactualizados para el propósito actual.

(b) Los psicólogos no basan tales decisiones o recomendaciones en tests y medidas que son obsoletas y no son útiles para el propósito actual. 
Fernández-

Ballesteros

(2013).

OMS

(2017).
52. Las fuentes de información, los instrumentos y tests utilizados quedarán reflejados con el suficiente detalle.

Pauta 4. Los países tienen la obligación de asegurar que los datos recolectados sean de calidad suficiente, oportunos, fidedignos y válidos para lograr los objetivos de salud pública.

\section{Tabla 6.}

Documentos de apoyo relativos al proceso de evaluación, hipótesis y conclusiones.

\section{$\begin{array}{ll}\text { Fuente } & \text { Artículo/numeral }\end{array}$}

9.01. Bases para la evaluación.

(a) Los psicólogos basan las opiniones contenidas en sus recomendaciones, informes y diagnósticos o evaluaciones, inclusive los testimonios forenses, en información y técnicas adecuadas para sustentar sus conclusiones.

APA (b) Excepto en los casos estipulados en la norma 9.01c, los psicólogos ofrecen opiniones sobre las características psicológicas de los individuos, sólo después de haber realizado un examen adecuado para sustentar sus declaraciones o conclusiones. (2017). Cuando a pesar de haber realizado los esfuerzos razonables, dicho examen no sea factible, los psicólogos documentan los y validez de sus opiniones y establecen adecuadamente los límites de la naturaleza y el alcance de sus conclusiones o recomendaciones y opiniones, y establecen adecuadamente los límites de la naturaleza y el alcance de sus conclusiones o recomendaciones.

Fernández- 45. El informe incluirá un resumen con las conclusiones más importantes.

Ballesteros 53. El informe detallará los pasos y procedimientos utilizados para responder a las demandas del cliente.

(2013). 65 . El evaluador reflejará en el informe las cuestiones surgidas durante la información de resultados y de recomendaciones, en la versión final de éste.

Mancilla

- Resultados de las pruebas: C.I. cuantitativo y cualitativo, daño orgánico cerebral, disfunción cerebral, personalidad, (2011). con qué partes sanas o recursos cuenta el paciente. Este último aspecto es esencial para el pronóstico.

- Recomendaciones o sugerencias. Éstas deben ser claras, concretas, individualizadas, tratamiento, pronóstico.

IMSS 7.2.3.24. La dirección de la unidad hospitalaria psiquiátrica, a solicitud escrita del paciente, familiar, tutor o (2020). representante legal, proporcionará un resumen clínico sobre el diagnóstico, evolución, tratamiento y pronóstico del

Tabla 7.

Documentos de apoyo relativos al estilo de redacción del IPC.

FUENTE

SMP

(2010).

Fernández-

Ballesteros

(2013).

Mancilla

(2011).

\section{Artículo/NUMERAL}

Art. 38. El psicólogo procura asegurar que los enunciados o declaraciones relativas al lineamiento de sus cursos o materiales sean precisos y no resulten engañosos, particularmente en lo relativo a los temas y materiales cubiertos, las bases para la evaluación y la naturaleza de la experiencia del curso.

57. Cada una de las frases empleadas será clara y comprensible para el cliente.

58. El apoyo científico de un enunciado se explicitará siempre que exista la posibilidad de que se malinterprete.

59. La terminología técnica utilizada debe clarificarse de la forma apropiada.

60. Los elementos descriptivos, comparativos e interpretativos se distinguirán entre sí.

61. La interpretación de los datos no se dejará en manos del lector.

62. Las conclusiones se expondrán con claridad, y las inferencias tentativas se señalan como tales.

1. Lenguaje bien definido, específico y concreto: específico, no general, definido, no vago, concreto, no abstracto.

2. No sacrificar la claridad, por lo tanto no abreviar, no siglas como WAIS, DFH, HTP.

3. Ser claro, no enigmático: quién dijo, quién es...

4. Evitar palabras rebuscadas.

5. Evitar palabras innecesarias: frases de adornos; ejemplo: “su hermano que también es miembro del mismo club, porque tiene buenos ingresos...".

6. Agrupar la información que se refiere a lo mismo, ideas afines, por ejemplo, el desarrollo temprano, las fechas de los ingresos, si los hay.

7. No ser jactancioso o crítico o exagerado: pueden creer que fue capaz de...

8. No exagerar: no usar superlativos o ser muy categórico: "no existe...", "es muy...".

5.11. Las notas en el expediente deberán expresarse en lenguaje técnico-médico, sin abreviaturas, con letra legible, sin enmendaduras ni tachaduras, y conservarse en buen estado. 
CNB

(2015).

El proceso de información: El personal de salud debe asegurarse que el paciente o los familiares responsables han comprendido la información proporcionada y deben propiciar que éstos realicen preguntas para dar las respuestas correspondientes en forma comprensible. Se debe considerar el nivel de educación y los antecedentes socioculturales de los participantes y tratar de utilizar un lenguaje apropiado.

Tabla 8.

Documentos de apoyo relativos a la confidencialidad y el secreto profesional.

FUENTE

Artículo 67. El psicólogo no menciona en sus trabajos escritos o al dar clases o conferencias, o por otros medios públicos, información confidencial obtenida durante el curso de su trabajo, en que se identifiquen personas o grupos, sean éstos sus pacientes, clientes individuales u organizaciones, estudiantes, sujetos de investigación u otros receptores de sus servicios, a menos que estas personas u organizaciones den su consentimiento por escrito, o que haya otra autorización ética o legal para hacerlo.

Artículo 68. En sus presentaciones científicas o profesionales y publicaciones, el psicólogo disfraza la información confidencial de personas u organizaciones, de modo que otros no puedan identificarlas y que las discusiones resultantes no dañen a los sujetos que pudiesen identificarse a sí mismos.

Artículo 132. El psicólogo tiene la obligación básica de respetar los derechos a la confidencialidad de aquellos con quienes trabaja o le consultan, reconociendo que la confidencialidad puede establecerse por ley, por reglas institucionales o profesionales, o por relaciones científicas, y toma las precauciones razonables para tal efecto.

Artículo 133. Con el fin de minimizar intrusiones en la privacía el psicólogo sólo incluye en sus informes escritos u orales, consultorías o asesorías y similares, aquella información pertinente al propósito de dicha comunicación.

SMP (2010). Artículo 134. El psicólogo discute la información confidencial obtenida en relaciones clínicas o de consultoría, o los datos de valoración relativa a pacientes y clientes, ya sean individuos u organizaciones, estudiantes, sujetos o participantes en investigación supervisados y empleados, únicamente para los propósitos apropiados de tipo científico o profesional, y sólo con las personas clara y adecuadamente relacionadas con dichos asuntos. El psicólogo muestra información confidencial sin consentimiento del individuo, sólo cuando le obligue la ley o cuando éste le permita para propósitos válidos tales como: 1. Proveer servicios profesionales necesarios al paciente o al cliente individual u organización.

2. Para obtener consultoría o asesoría profesional apropiada.

3. Para proteger al paciente, cliente u otros, de algún daño.

4. Para obtener el pago de servicios, en cuyo caso la información que muestre se limitará al mínimo necesario para lograr dicho propósito, o

5. Actuar como psicólogo perito, auxiliar de la administración de la justicia, en cuyo caso proporciona todos los elementos técnicos, científicos y relativos a los resultados de evaluaciones psicológicas para formar la convicción de un juez.

Artículo 137. El psicólogo puede mostrar información confidencial siempre y cuando cuente con el consentimiento escrito del paciente o del cliente individual u organización (o de otra persona legalmente autorizada en representación de éstas), a menos que esta ley lo prohíba.

4.01. Mantenimiento de la confidencialidad. Los psicólogos tienen como obligación primordial, y toman las precauciones razonables para, proteger la información confidencial obtenida o conservada por cualquier medio, reconociendo que los alcances y límites de la confidencialidad pueden ser regulados por ley, o establecidos por reglas institucionales o por relaciones profesionales o científicas.

4.02. Discusión de los límites de la confidencialidad.

(a) Los psicólogos discuten con las personas (incluyendo, en la medida de lo posible, a las personas legalmente incapaces de dar consentimiento y a sus representantes legales) y organizaciones con quienes establecen una relación científica o profesional, (1) las limitaciones relevantes en la confidencialidad y (2) los usos previsibles de la información obtenida a través de sus actividades psicológicas.

(b) A menos que no sea factible o esté contraindicado, la discusión acerca de la confidencialidad tiene lugar al comienzo de la relación y de allí en adelante según lo garanticen las circunstancias.

(c) Los psicólogos que ofrecen servicios, productos o información por vías de transmisión electrónica informarán a sus clientes/pacientes sobre los riesgos de la privacidad y los límites de la confidencialidad.

5.4. Los expedientes clínicos son propiedad de la institución o del prestador de servicios médicos que los genera, cuando éste no dependa de una institución. En caso de instituciones del sector público, además de lo establecido en esta norma deberán observar las disposiciones que en la materia estén vigentes. Sin perjuicio de lo anterior, el paciente en tanto aportante de la información y beneficiario de la atención médica tiene derechos de titularidad sobre la información para la protección de su salud, así como para la protección de la confidencialidad de sus datos, en los términos de esta norma y demás disposiciones jurídicas que resulten aplicables.

5.5.1. Datos proporcionados al personal de salud, por el paciente o por terceros, mismos que, debido a que son datos personales, son motivo de confidencialidad, en términos del secreto médico profesional y demás disposiciones jurídicas que resulten aplicables. Únicamente podrán ser proporcionados a terceros cuando medie la solicitud escrita del paciente, el tutor, representante legal o de un médico debidamente autorizado por el paciente, el tutor o representante legal.

Ley General de Artículo 77 BIS 37. Los beneficiarios del Sistema de Protección Social en Salud tendrán derecho a:

Salud (2021). X. Ser tratados con confidencialidad. 
Ley Federal de Transparencia y Acceso a la Información Pública (2016).

Tiene como finalidad proveer las acciones necesarias para garantizar el acceso de toda persona a la información en posesión de los Poderes de la Unión, los órganos constitucionales autónomos o con autonomía legal, y cualquier otra entidad federal. Además, en ella se encuentran establecidas las garantías para que los datos personales que los organismos públicos tienen en sus registros se protejan adecuadamente. Esta ley indica los parámetros para conocer bajo qué circunstancias los datos deben ser considerados reservados o confidenciales. El conocimiento de esta ley es de gran relevancia para los servidores públicos, pues en ella se establecen las obligaciones que adquieren al tener acceso a datos personales, así como los márgenes adecuados de su tratamiento, es decir, cuándo pueden ser dados a conocer, a quién y en qué condiciones, así como las circunstancias en las que se requiere autorización de los individuos para su difusión o distribución. A las normas contenidas en esta ley debe adicionarse lo establecido en la Ley General de Salud y su Reglamento en Materia de Prestación de Servicios de Atención Médica, en lo relativo al cuidado de la confidencialidad de datos personales.

Pauta 11. En ciertas circunstancias se justifica la recolección de nombres o datos que permitan identificar a las personas.

Pauta 12. Las personas tienen la obligación de contribuir con la vigilancia cuando se requieran conjuntos de datos fiables, válidos y completos, y se cuente con la debida protección. En estas circunstancias el consentimiento informado no es un requisito ético.

Pauta 17. Los datos de vigilancia con información que permita identificar a las personas no deberían compartirse con organismos que probablemente los usen para adoptar medidas contra las personas o para otros propósitos no relacionados con la salud pública.

\subsubsection{Confidencialidad.}

Deberían existir normas legislativas que aseguren que toda la información y documentos acerca de los trastornos mentales de una persona se tratarán de manera confidencial. Las leyes deberían prohibir explícitamente la divulgación, inspección o transmisión de los documentos de salud mental del paciente sin su consentimiento y/o el de su representante o tutor legal. De manera similar, la legislación debería exigir que los profesionales obtengan el consentimiento del paciente antes de divulgar cualquier tipo de información no escrita obtenida durante la evaluación y tratamiento de trastornos mentales. También es importante tener en cuenta las necesidades de los cuidadores y de las familias.

Deberían tener a su disposición la información adecuada y apropiada para que así ellos puedan proporcionar los cuidados necesarios a pacientes que viven en el hogar. La legislación debe luchar por lograr el equilibrio entre el principio de confidencialidad y la necesidad de información que precisan los cuidadores y familiares para poder atender a los pacientes de manera apropiada.

Tabla 9.

Documentos de apoyo relativos al consentimiento informado.

Artículo 118. El psicólogo obtiene consentimiento informado apropiado a la terapia, investigación u otros procedimientos, utilizando un lenguaje entendible para los participantes. El contenido del consentimiento informado variará dependiendo de muchas circunstancias; sin embargo, generalmente supone que la persona:

1. posee la capacidad para consentir,

2. se le ha proporcionado la información significativa concerniente al procedimiento,

3. ha expresado libremente y sin influencias indebidas su consentimiento, y

4. el consentimiento se ha documentado en forma apropiada.

Artículo 119. Cuando las personas presenten incapacidad legal para dar un consentimiento informado, el psicólogo lo obtiene de una persona legalmente autorizada.

Artículo 120. El psicólogo:

1. explica a las personas legalmente incapaces de consentir informadamente acerca de las intervenciones propuestas de manera conmensurable a las capacidades psicológicas de estas personas,

2. busca su asentimiento para esas intervenciones, y

3. considera las preferencias y mejores intereses de tales personas.

SMP (2010). Artículo 121. El psicólogo obtiene permiso y consentimiento de los pacientes, clientes, sujetos de investigación, estudiantes y supervisados para el registro o grabación electrónica de sesiones o entrevistas o si requiere que revelen situaciones personales.

Artículo 122. El psicólogo que realiza una investigación o estudio, bajo cualquier circunstancia, obtiene consentimiento informado de los participantes. El psicólogo utiliza lenguaje que sea entendible para los participantes en la investigación o de las personas legalmente autorizadas, al obtener su consentimiento informado. Tal consentimiento se documenta de manera apropiada. Con lenguaje entendible para los participantes, el psicólogo les informa de la naturaleza de la investigación que tienen la libertad de participar o de declinar, o de retirarse de la investigación; les explica las consecuencias predecibles de declinar o de retirarse; les hace saber de factores significativos que deban esperarse de su disposición a participar (tales como riesgos, incomodidad, efectos adversos, o limitaciones sobre la confidencialidad).

Artículo 124. En los casos en los que las personas sean menores de edad o incapaces legalmente de dar su consentimiento informado, el psicólogo, no obstante:

1.proporciona una explicación apropiada,

2.obtiene el asentimiento del participante, o

3.de una persona autorizada legalmente, en caso de que la ley permita tal consentimiento sustituto. 
Introducción. En el marco del ejercicio de los derechos del paciente, esta norma ratifica la importancia de que la autoridad sanitaria garantice la libre manifestación de la voluntad del paciente de ser o no atendido a través de procedimientos clínicos o quirúrgicos, para lo cual el personal de salud debe recabar su consentimiento, previa

SSA (2012). $\quad$ información y explicación de los riesgos posibles y beneficios esperados. legal o familiar más cercano en vínculo, mediante los cuales se acepta un procedimiento médico o quirúrgico con fines diagnósticos, terapéuticos, rehabilitatorios, paliativos o de investigación, una vez que se ha recibido información de los riesgos y beneficios esperados para el paciente.

Artículo 74. La atención de los trastornos mentales y del comportamiento comprende:

III. Derecho al consentimiento informado de la persona o su representante, en relación al tratamiento a recibir. VIII. Derecho a la confidencialidad de la información psiquiátrica sobre su persona.

Ley General de Salud (2021).

Artículo 77 BIS 37. Los beneficiarios del Sistema de Protección Social en Salud tendrán además de los derechos establecidos en el artículo anterior, los siguientes.

IX. Otorgar o no su consentimiento válidamente informado y a rechazar tratamientos o procedimiento.

$X$. Ser tratado con confidencialidad.

3.10. Consentimiento informado.

(a) Cuando los psicólogos conducen investigaciones o presten servicios de evaluación, terapia, consejería, de manera presencial o por vías de transmisión electrónica u otras formas de comunicación, obtienen el consentimiento informado del o los individuos utilizando un lenguaje que sea razonablemente comprensible para la o las personas, excepto cuando llevar adelante tales actividades sin consentimiento esté autorizado por ley o regulaciones gubernamentales, o esté establecido en este Código de Ética.

(b) En el caso de las personas legalmente incapaces para dar consentimiento informado, los psicólogos igualmente (1) proveen una explicación apropiada, (2) procuran el acuerdo del individuo, (3) consideran las preferencias y los mejores intereses de tales personas, y (4) obtienen el permiso apropiado de una persona legalmente autorizada, si tal consentimiento sustituto está permitido o requerido por ley. Si no lo estuviera, los psicólogos toman las medidas razonables para proteger los derechos y el bienestar del individuo.

(c) Cuando los servicios psicológicos sean indicados o autorizados por la justicia, los psicólogos informarán al individuo antes de proceder sobre la naturaleza de dichos servicios, incluyendo si fueron o no indicados o autorizados por la justicia y los límites de la confidencialidad.

(d) Los psicólogos documentan apropiadamente el consentimiento escrito u oral, el permiso y el asentimiento.

4.05. Revelación de información.

(a) Los psicólogos pueden revelar la información confidencial con el apropiado consentimiento de la empresa/ cliente, el cliente/paciente individual u otra persona legalmente autorizada en nombre del cliente/paciente, excepto en los casos que esté específicamente prohibido por ley.

(b) Los psicólogos revelan información confidencial sin el consentimiento del individuo en los casos que indica la ley, o cuando ésta lo permita para fines legítimos, tales como (1) proveer servicios profesionales necesarios; (2) obtener consultas profesionales apropiadas; (3) proteger al cliente/paciente, al psicólogo o a otras personas de daño; y (4) obtener del cliente/paciente el pago de los servicios, en cuyo caso la revelación estará limitada al mínimo necesario para alcanzar tal propósito.

10.01. Consentimiento informado a la terapia.

(a) Al obtener el consentimiento informado para la terapia como se requiere en el estándar, los psicólogos informan a los clientes/pacientes tan pronto como sea posible en la relación terapéutica sobre la naturaleza y el curso anticipado de la terapia, los honorarios, la participación de terceros y los límites. de confidencialidad y brindan oportunidades suficientes para que el cliente/paciente haga preguntas y reciba respuestas.

(b) Al obtener el consentimiento informado para el tratamiento para el cual no se han establecido técnicas y procedimientos generalmente reconocidos, los psicólogos informan a sus clientes/pacientes sobre la naturaleza en desarrollo del tratamiento, los riesgos potenciales involucrados, los tratamientos alternativos que pueden estar disponibles y el voluntariado naturaleza de su participación.

(c) Cuando el terapeuta es un aprendiz y la responsabilidad legal del tratamiento proporcionado recae en el supervisor, el cliente/paciente, como parte del procedimiento de consentimiento informado, es informado de que el terapeuta está en capacitación y está siendo supervisado y se le da el nombre del supervisor.

Consentimiento informado y asentimiento. El consentimiento informado es la expresión tangible del respeto a la autonomía de las personas en el ámbito de la atención médica y de la investigación en salud. Es un proceso continuo y gradual que se da entre el personal de salud y el paciente y que se consolida en un documento. Mediante el consentimiento informado el personal de salud le informa, en calidad y en cantidad suficiente al paciente competente, sobre la naturaleza de la enfermedad y del procedimiento diagnóstico y/o terapéutico que se propone utilizar, los riesgos y beneficios que éste conlleva, así como las posibles alternativas. El documento escrito sólo es el resguardo de que el personal de salud ha informado y de que el paciente ha comprendido en su totalidad

CNB (2015). la información. Por lo tanto, el consentimiento informado es la manifestación de la actitud responsable y bioética del personal médico o de investigación en salud, que eleva la calidad de los servicios y que garantiza el respeto a la dignidad y a la autonomía de las personas.

El consentimiento informado se diferencia del asentimiento, en que este último es la aceptación de un incapaz previamente informado sobre su diagnóstico, alternativas de tratamiento, beneficios, alcances, riesgos y consecuencias, para recibir un tratamiento o participar en una investigación. Señala la voluntad de cooperación del incapaz. Debido a que los valores u objetivos de las personas varían, la mejor elección no siempre es la que prioriza a la salud, sino la que prioriza el máximo bienestar de acuerdo a los valores u objetivos de cada persona. 
Pauta 12. Las personas tienen la obligación de contribuir con la vigilancia cuando se requieran conjuntos de datos fiables, válidos y completos y se cuente con la debida protección. En estas circunstancias, el consentimiento informado no es un requisito ético

\subsubsection{Consentimiento informado.}

Para que sea válido, el consentimiento debe satisfacer los siguientes criterios (Principios MI y Directrices para los Principios MI):

a) La persona/paciente que da el consentimiento debe ser valorada como competente y capaz de dar consentimiento.

b) El consentimiento debe darse voluntariamente, sin amenazas o presiones inadecuadas.

OMS (2003). c) Debe haber una información adecuada sobre el objetivo, método, duración estimada y beneficios previstos del tratamiento propuesto.

f) La información pertinente debe proporcionarse con un lenguaje claro y de forma llana para que el paciente la pueda comprender.

g) El paciente debe tener el derecho a rechazar o finalizar el tratamiento.

h) Se deben explicar al paciente las consecuencias de rechazar el tratamiento.

Tabla 10.

Documentos de apoyo relativos a la protección de documentos y datos personales.

FUENTE

SMP (2010).

SSA (2012)

OMS (2017).

Ley Federal de Protección de datos Personales en Posesión de Sujetos Obligados (2018).

\section{Artículo/NUMERAL}

Artículo 52. El psicólogo se abstiene de hacer uso indebido de las técnicas de valoración, intervenciones, resultados e interpretaciones, y toma las medidas razonables para evitar que otros hagan mal uso de éstas. Esto incluye el abstenerse de ceder resultados crudos de pruebas a personas que no sean los pacientes o clientes como es apropiado, y a quienes no están calificadas para usar tal información. Artículo 53. El psicólogo documenta apropiadamente su trabajo profesional y científico para facilitar la prestación posterior de servicios por parte de él mismo o de otros profesionales, para asegurar responsabilidad, y para cumplir con otros requisitos de instituciones o la ley. El psicólogo se abstiene de externar opiniones acerca de individuos a los cuales no ha valorado debidamente, en dictámenes escritos o verbales, medio de comunicación alguno o en cualquier forma.

Artículo 54. Cuando el psicólogo tiene razones para creer que los archivos de sus servicios profesionales se van a usar en asuntos legales involucrando receptores de su trabajo o participantes en su trabajo, tiene la responsabilidad de crear y mantener la documentación con tal detalle y calidad que sea congruente con el escrutinio razonable de un foro adjudicador. El psicólogo crea, mantiene, disemina, almacena, retiene, y desecha archivos o expedientes y datos relacionados con su investigación práctica y demás trabajo de acuerdo con la ley y de una manera que permita cumplir con los requerimientos de este Código Ético.

5.7. En los establecimientos para la atención médica, la información contenida en el expediente clínico será manejada con discreción y confidencialidad, por todo el personal del establecimiento, atendiendo a los principios científicos y éticos que orientan la práctica médica, así como las disposiciones establecidas en la Norma Oficial Mexicana, referida en el numeral 3.14 de esta norma y demás disposiciones jurídicas aplicables.

7.1.4. El personal de salud y administrativo que realiza actividades en los servicios a la población derechohabiente que presente algún trastorno mental y del Comportamiento deberán asegurar que los datos personales de los derechohabientes y no derechohabientes atendidos, observen el manejo que establece la Ley Federal de Transparencia y Acceso a la Información Pública, publicada en el Diario Oficial de la Federación el 09 de mayo del 2016 y sus reformas y la Ley General de Transparencia y Acceso a la Información Pública, publicada en el Diario Oficial de la Federación el 04 de mayo de 2015 y sus reformas. 7.2.3.28. La información proporcionada por el paciente, familiar, tutor o representante legal, ya sea verbal o por otros medios de comunicación, deberá ser manejada bajo las leyes de protección de datos e información personal, los principios éticos y de confidencialidad.

Pauta 10. Los gobiernos y otras entidades que tienen datos de vigilancia en su poder deben de mantener debidamente resguardados los datos que permiten identificar a las personas.

Esta ley tiene por objeto la protección de los datos personales en posesión de los particulares, con la finalidad de regular su tratamiento legítimo, controlado e informado, a efecto de garantizar la privacidad y el derecho a la autodeterminación informativa de las personas. En atención a lo anterior, las instituciones del sector privado que presten servicios de salud deben tener en cuenta lo previsto en este ordenamiento para que los datos personales a que tienen acceso se encuentren protegidos adecuadamente.

Artículo 12. El responsable deberá contar con el consentimiento previo del titular para el tratamiento de los datos personales. Artículo 14. Por regla general no podrán tratarse datos personales sensibles, salvo que se cuente con el consentimiento previo, expreso, informado e inequívoco de su titular, a través de su firma autógrafa, firma electrónica o cualquier mecanismo de autenticación que al efecto se establezca o, en su caso, se trate de las excepciones establecidas en la presente Ley. Artículo 64. El responsable podrá realizar transferencias de datos personales sin necesidad de requerir el consentimiento del titular, en los siguientes supuestos:

III. Cuando la transferencia sea legalmente exigida para la investigación y persecución de los delitos, así como la procuración o administración de justicia. 
Tabla 11.

Muestra una síntesis de las diez recomendaciones y los documentos de apoyo encontrados

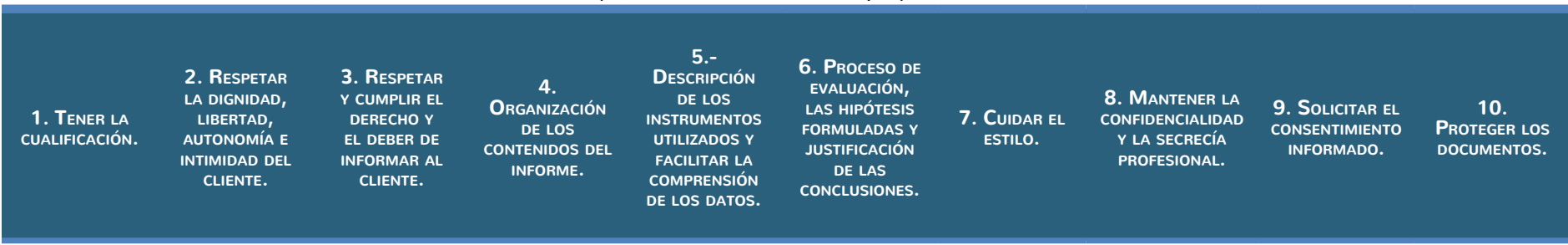

\begin{tabular}{|c|c|c|c|c|}
\hline $\begin{array}{l}\text { Ley General de } \\
\text { Salud (2021). } \\
\text { Congreso de los } \\
\text { Estados Unidos } \\
\text { Mexicanos (2). }\end{array}$ & CNB (2010). (5). & $\begin{array}{l}\text { SSA (2012). } \\
\text { Norma Oficial } \\
\text { Mexicana NOM- } \\
\text { 004-SSA3-2012, } \\
\text { Del expediente } \\
\text { clínico (1). }\end{array}$ & $\begin{array}{l}\text { Mancilla (2011). } \\
\text { (13). }\end{array}$ & $\begin{array}{l}\text { SMP (2010). } \\
\text { Código de Ética } \\
\text { del Psicólogo } \\
\text { (8). }\end{array}$ \\
\hline
\end{tabular}

$\begin{array}{lllll} & & & \text { Fernández- } & \text { Fernández- } \\ \text { SMP (2010). } & \text { SMP (2010). } & \text { SMP (2010). } & \text { Ballesteros } & \text { Ballesteros } \\ \text { Código de Ética } & \text { Código de Ética } & \text { Código de Ética } & \text { (2013). Guías } & \text { (2013). Guías } \\ \text { del Psicólogo } & \text { del Psicólogo } & \text { del Psicólogo } & \text { del Proceso } & \text { del Proceso } \\ \text { (8). } & \text { (16). Evaluación } & \text { de Evaluación } \\ & & \text { (5). } & \begin{array}{l}\text { Psicológica } \\ \text { Psicológica }\end{array} & \begin{array}{l}\text { Psicolor } \\ \text { (GAP) (13). }\end{array} \\ & & & \text { (GAP) (1). }\end{array}$
APA (2017).
Ethical principles
of psychologists
and code of
conduct (2).

SMP (2010), del Psicólogo (1).

Fernández-
Ballesteros
(2013). Guías
del Proceso
de Evaluación
Psicológica
(GAP) (3).

APA (2017)

APA (2017). of psychologists and code of
conduct (2). Ethical principles and code of conduct (3)

APA (2017).

Ethical principles of psychologists conduct (1).

CNB (2015). (1) of psychologists conduct (4).

Fernández-
Ballesteros
(2013). Guías
del Proceso
de Evaluación
Psicológica
(GAP) (6).

Código de Ética SMP (2010).
APA (2017).
Ethical principles of psychologists and code of conduct (5).
SSA (2012). Mexicana NOM 004-SSA3-2012, Del expediente clínico (2).
SMP (2010), SMP (2010). Cól Psicólogo É Código de Ética (16).

APA (2017). SSA (2012) Ethical principles Norma Oficial of psychologists 004-SSA3-2012, and code of conduct. (12) clínico (2).

Ley Federal de Protección SSA (2012) Norma Oficial Mexicana NOMDel expediente clínico (2) de Datos Personales en Posesión de Sujetos Obligados INFOCDMX (5).

Fernández-
Ballesteros
(2013). Guías
del Proceso
de Evaluación
Psicológica
(GAP) (1).

Ley de Salud
Mental del
Distrito
Federal (2011).
Asamblea
Legislativa del
Distrito Federal
(3).

SSA (2014) Norma Oficial Mexicana NOM 025-SSA2-2014. Para la

prestación

de servicios

de salud en

unidades de

atención integral

hospitalaria

psiquiátrica (3).

FernándezBallesteros (2013). Guías del Proceso de Evaluación Psicológica
IMSS (2020).

OMS (2017). Pautas de la ÓMS sobre la vigilancia de la
vica sobre la IMSS (2020) (1) SSA (2012). Norma Oficial Mexicana SSA3-2012, Del expediente Ley General de Salud (2021). Congreso de los tados Unidos Mexicanos (2).

Ley General de IMSS (2020) salud (4). Salud (2021). Congreso de los Estados Unidos Mexicanos (3).

Ley General de Salud (2021). Congreso de los Estados Unidos Mexicanos (3).

OMS (2017) Pautas de la ética sobre la vigilancia de la

SSA (2014).

NORMA Oficial

Mexicana NOM-

025-SSA2-2014

Para la

prestación

de servicios

de salud en

atención integral

hospitalaria

psiquiátrica (1).

Ley de Salud

Mental del

Mistrito

Federal (2011).

Asamblea

Legislativa del

(1).

IMSS (2020)

(1).

OMS (2017).

Pautas de la

OMS sobre la

ética sobre la

vigilancia de la OMS sobre la
CNB (2015). Transparencia

(1).

y Acceso a la

Pública (2016). (1).

OMS (2017).

Pautas de la

ética sobre la

vigilancia de la salud (1).
OMS (2017)

Pautas de la OMS

sobre la ética

(3) sobre la vigilancia

de la salud pública

OMS (2017)

Pautas de la

OMS sobre la

ética sobre la

valud pública (1). 


\section{Meta-Análisis del Artículo}




\section{Dimensión Cuantitativa}

\section{Perfil de Evaluación entre pares}
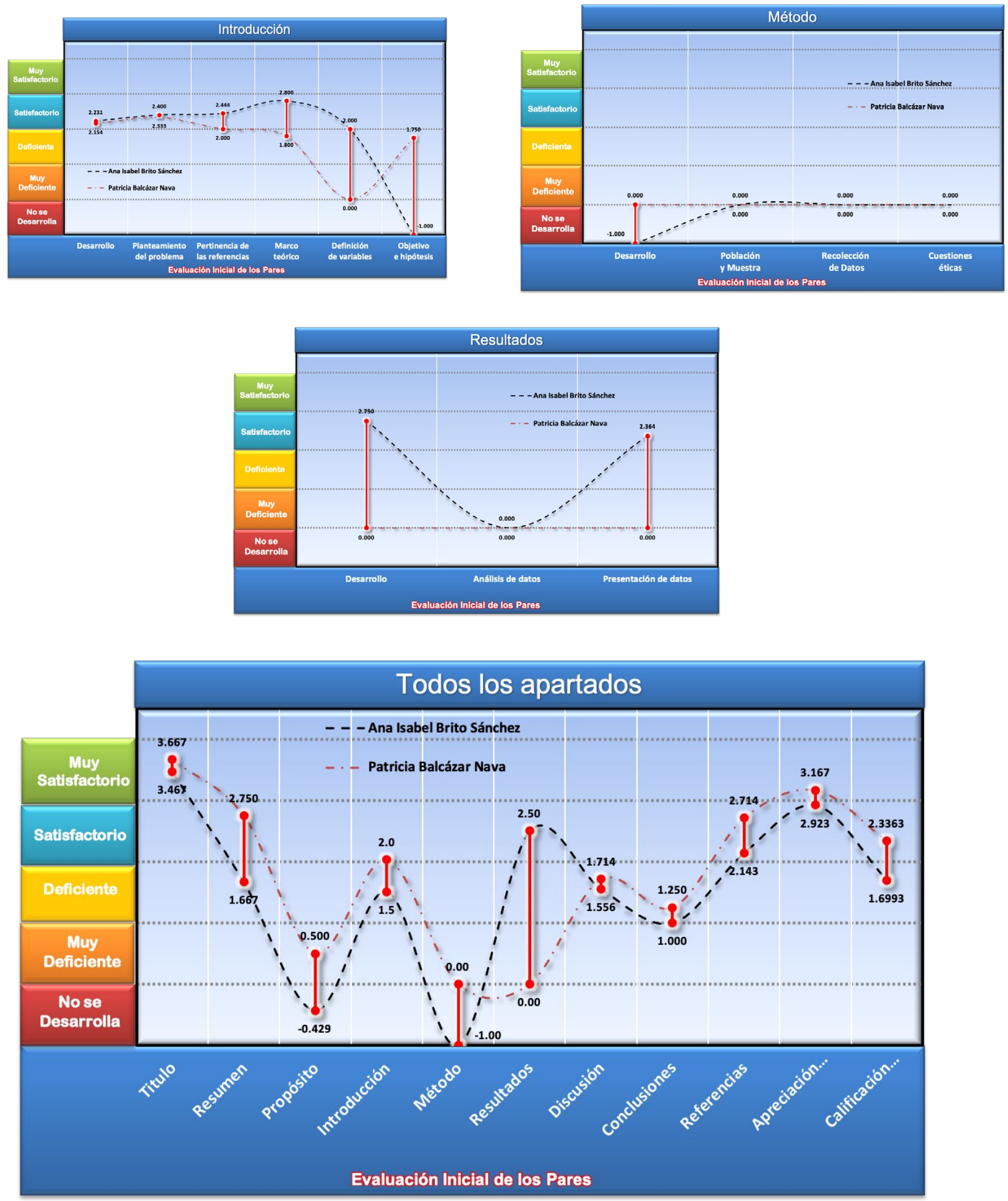


\section{Índice de Concordancia}

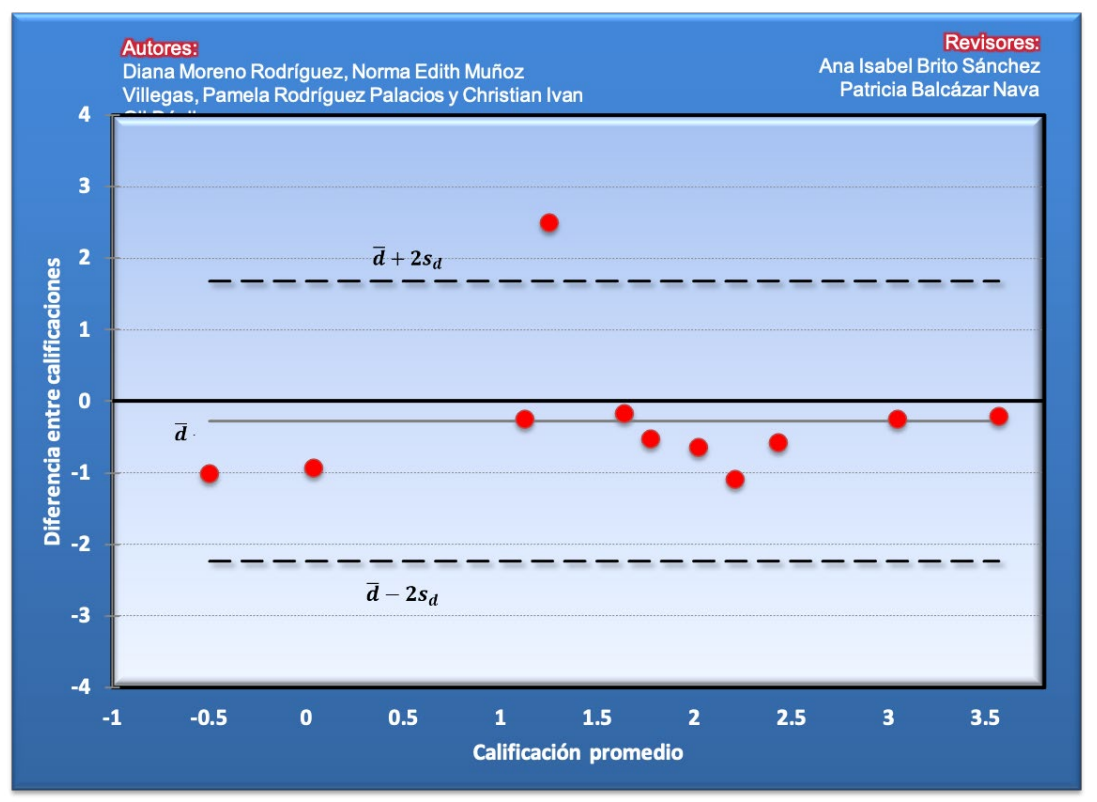

\section{Índice de Acuerdo}

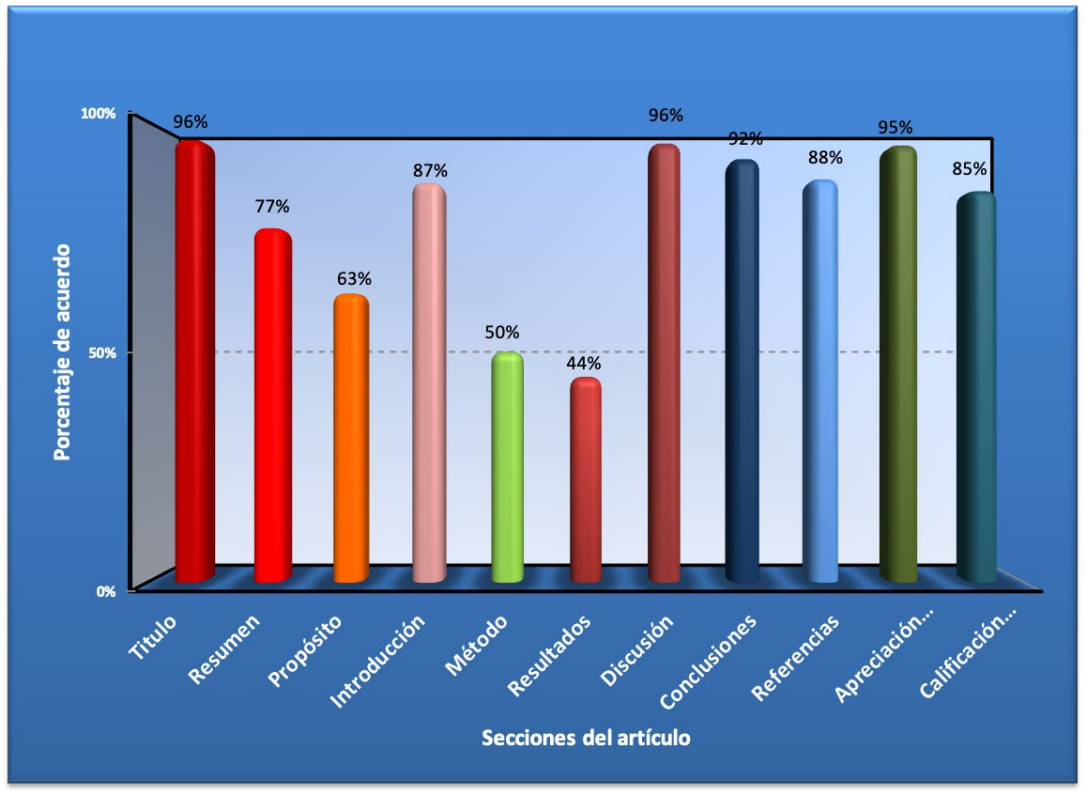




\begin{tabular}{|c|c|}
\hline Revisor 1 & Revisor 2 \\
\hline Ana Isabel Brito Sánchez & Diana Elisabeth Reza Morales \\
\hline \multicolumn{2}{|c|}{ Título/Autoría } \\
\hline $\begin{array}{l}\text { Las palabras claves del artículo y el título del mismo se } \\
\text { relaciona sólo parcialmente }\end{array}$ & En el título reemplazar; por : \\
\hline \multicolumn{2}{|c|}{ Resumen } \\
\hline $\begin{array}{l}\text { Dentro del resumen no se hace referencia al cómo se lle- } \\
\text { gó a las recomendaciones que refieren, así mismo hacen } \\
\text { falta las conclusiones, se queda sólo explicando los resul- } \\
\text { tados. Estos dos aspectos son claves dentro del resumen. } \\
\text { Por otro lado se necesita hacer de forma más concreta, } \\
\text { pues excede por mucho las palabras solicitadas. }\end{array}$ & $\begin{array}{l}\text { 1)Se sugiere mejorar la redacción para que sea más clara la } \\
\text { conexión entre las ideas. 2) Se pueden ocupar sinónimos } \\
\text { para que las palabras no sean tan repetitivas. 3) Agregar } \\
\text { palabras clave. }\end{array}$ \\
\hline \multicolumn{2}{|c|}{ Próposito del Estudio } \\
\hline $\begin{array}{l}\text { En la redacción del artículo se pone un breve párrafo } \\
\text { hablando de lo que se va a generar, sin embargo en nin- } \\
\text { gún momento se explica el propósito, ni se plantean las } \\
\text { preguntas a contestar con el mismo, ni la metodología } \\
\text { que se usará. }\end{array}$ & $\begin{array}{l}\text { En el análisis conceptual que se propone dentro del tex- } \\
\text { to, hace falta citar a los autores, con la finalidad de brin- } \\
\text { dar un sustento sólido al argumento. }\end{array}$ \\
\hline \multicolumn{2}{|c|}{ Introducción } \\
\hline $\begin{array}{l}\text { La revisión teórica no es exhaustiva y las referencias utili- } \\
\text { zadas no son actuales; no se explica en ningún momento } \\
\text { de forma clara el objetivo de la revisión que se hará ni cuá- } \\
\text { les son los resultados que se quieren obtener. Se pueden } \\
\text { deducir las variables del trabajo, sin embargo no se expo- } \\
\text { nen de manera clara }\end{array}$ & $\begin{array}{l}\text { Para brindar solidez al trabajo se recomienda agregar más } \\
\text { referencias de autores que hablen de las conductas desvia- } \\
\text { das/antisociales/contraproducentes en las organizaciones, } \\
\text { complementando con estudios que den sustento a la vali- } \\
\text { dez de tales definiciones. }\end{array}$ \\
\hline \multicolumn{2}{|c|}{ Método } \\
\hline $\begin{array}{l}\text { Sólo se hace una revisión teórica y se plantean unas pre- } \\
\text { cisiones teóricas, pero no se hace referencia a cómo lo } \\
\text { hacen, que pasos se siguieron para los resultados que } \\
\text { obtienen. Por otro lado se habla de la práctica clínica en } \\
\text { México y él que hacer del psicólogo en México, utiliza le- } \\
\text { yes y normas de otros países, sin hacer una justificación } \\
\text { o análisis de los mismos. }\end{array}$ & $\begin{array}{l}\text { Ningún comentario, ya que esta sección no aplica para un } \\
\text { artículo de revisión teórica. }\end{array}$ \\
\hline
\end{tabular}




\begin{tabular}{|c|c|}
\hline Revisor 1 & Revisor 2 \\
\hline \multicolumn{2}{|c|}{ Resultados } \\
\hline $\begin{array}{l}\text { Las tablas no tienen explicación dentro del texto y al no } \\
\text { tener planteado el objetivo desde un inicio de forma clara, } \\
\text { se dificulta el hacer la redacción de resultados. }\end{array}$ & No aplica \\
\hline \multicolumn{2}{|c|}{ Discusión } \\
\hline $\begin{array}{l}\text { La discusión no se encuentra fundamentada, es vaga y } \\
\text { no se hablan de las limitaciones del estudio. }\end{array}$ & $\begin{array}{l}\text { Agregar referencias para dar un sustento más sólido en el } \\
\text { apartado de análisis conceptual. }\end{array}$ \\
\hline \multicolumn{2}{|c|}{ Conclusiones } \\
\hline $\begin{array}{l}\text { La conclusión es pobre, no se discuten los hallazgos con } \\
\text { respecto a los objetivos que se tienen, y no se habla de las } \\
\text { líneas futuras. }\end{array}$ & $\begin{array}{l}\text { Se sugiere quitar del título la palabra revisión, ya que en } \\
\text { las conclusiones se comenta que no se hizo una revisión } \\
\text { del estado del arte de la temática, o bien especificar que } \\
\text { tipo de revisión se hizo desde un inicio. Ampliar las con- } \\
\text { clusiones con lo que se encontró a nivel conceptual, no } \\
\text { poner únicamente el recorrido que se hizo para efectuar } \\
\text { la investigación. }\end{array}$ \\
\hline \multicolumn{2}{|c|}{ Referencias } \\
\hline $\begin{array}{l}\text { El número de referencias consultadas es muy pobre y } \\
\text { suelen ser repetiitvas dentro del texto, se comenten al- } \\
\text { gunos errores de acuerdo al formato APA. Se utilizan un } \\
\text { número limitado de referencias actuales. Es difícil iden- } \\
\text { tificar algunas referencias, es especiales aquellas que ha- } \\
\text { cen referencia a documentos de asociaciones. }\end{array}$ & $\begin{array}{l}\text { 1) Verificar las citas al formato APA 6ta edición 2) Veri- } \\
\text { ficar errores en la escritura del nombre de los autores. 3) } \\
\text { Ampliar la cantidad de referencias de investigadores que } \\
\text { hablan del tema a nivel conceptual y empírico. }\end{array}$ \\
\hline
\end{tabular}




\section{Historia del Proceso \\ EDITORIAL}

